\title{
Numerical Analysis of Water Forced Convection in Channels with Differently Shaped Transverse Ribs
}

\author{
Oronzio Manca, Sergio Nardini, and Daniele Ricci \\ Dipartimento di Ingegneria Aerospaziale e Meccanica, Seconda Università degli Studi di Napoli, \\ Real Casa dell'Annunziata, Via Roma, 29, 81031 Aversa, Italy \\ Correspondence should be addressed to Oronzio Manca, oronzio.manca@unina2.it
}

Received 15 January 2011; Accepted 14 March 2011

Academic Editor: Shuyu Sun

Copyright (c) 2011 Oronzio Manca et al. This is an open access article distributed under the Creative Commons Attribution License, which permits unrestricted use, distribution, and reproduction in any medium, provided the original work is properly cited.

\begin{abstract}
Heat transfer enhancement technology has the aim of developing more efficient systems as demanded in many applications. An available passive method is represented by the employ of rough surfaces. Transversal turbulators enhance the heat transfer rate by reducing the thermal resistance near surfaces, because of the improved local turbulence; on the other hand, higher losses are expected. In this paper, a numerical investigation is carried out on turbulent water forced convection in a ribbed channel. Its external walls are heated by a constant heat flux. Several arrangements of ribs in terms of height, width, and shape are analyzed. The aim is to find the optimal configuration in terms of high heat transfer coefficients and low losses. The maximum average Nusselt numbers are evaluated for dimensionless pitches of 6, 8, and 10 according to the shape while the maximum friction factors are in the range of pitches from 8 to 10.
\end{abstract}

\section{Introduction}

Heat transfer enhancement technology plays an important role in the fields of engineering research and industry since every heat exchanger is virtually a potential candidate to be "enhanced". Several heat transfer augmentation techniques are developed in order to obtain size reductions, improve the thermodynamic process efficiency, or save costs. According to the thermal device and aims, different techniques are available. Their use is widely diffused in many applications as heat exchangers for refrigeration, automotive and aeronautic field, process industry, solar heaters, and so forth.

According to Bergles et al. [1] and Bergles [2], there are several enhancement techniques available. Thirteen different techniques are identified and grouped into "passive" and "active" ones, as pointed out by Webb and Kim [3]. Passive techniques employ special surface geometries, like coated surfaces, rough surfaces, extended surfaces or swirl flow 
devices, and fluid additives to obtain the enhancement targets. The active techniques need the supply of external power sources, such as mechanical aids, electric or acoustic fields, and surface vibration.

One of the possible solutions to enhance passively the heat transfer is represented by the employ of integral roughness [4-8]. Considerable data exist for single-phase forced convection flow over rough surface for geometries like flat plates, circular tubes, noncircular channels, longitudinal flows in rod bundles, annuli and flow orthogonal to circular tubes. Internally roughened geometries represent a reliable and widely adopted technology in several commercial applications as in evaporators [4], condensers [5], steam condensers [6], gas turbine blades refrigeration [7], solar heaters [8], and so forth.

Several experimental studies in this area have been accomplished, as showed for example in $[9,10]$ but actually a growing number of numerical investigation is carried out by adopting suitable means in order to overcome computational limitations and correctly describe the complexity of flow patterns [11]. In this work, an attempt is made to predict numerically the details of both the velocity and temperature fields responsible for heat transfer enhancement in water forced convection and quantify the effective improvement in terms of heat transfer rate analyzing the consequent increase of losses.

The use of artificial roughness in the form of repeated ribs has been found to be as an efficient method to enhance the heat transfer rates in forced convection, as pointed out by several investigators [12-16]. The integral ribs are generated on the heat transferring surface and their role consists into break the laminar sublayer near the wall and create local turbulence. In this way, the goal of the heat transfer augmentation is achieved by reducing the thermal resistance. The enhancement, due to the improved local turbulence caused by ribs, is significantly higher than the part obtained by the fin effect linked to the presence of turbulators, as underlined by Lee and Abdel-Moneim [17].

On the other hand, the use of artificial roughness produces higher friction losses leading to important power requirements for the fluids flow through duct and channels. It is consequently advisable to promote a stronger turbulence only in the region very close to the heat transferring surface, such as in the viscous sublayer, in order to generate a minimum disturb into the core flow. This may be obtained by keeping the height of roughness elements to be small in comparison with the duct dimensions [1].

The study on rough ducts and ribbed tubes dates back to Nikuradse [18], Dipprey and Sabersky [19], who developed the friction similarity law for heat and momentum transfer analogy for fluid flow in rough pipes, and Webb et al. [20] developed heat transfer and friction factor correlations for turbulent flow in tubes having rectangular repeated rib roughness. Their investigations inspired many researchers, who applied different modern approaches and instruments. For example, Liou and Hwang [14, 15] used a real-time Laser Holographic Interferometry (LHI) to measure the local as well as average heat transfer coefficient and compared the performance of square triangular and semicircular ribs and showed that the square-ribs give best heat transfer performance among them. For developing and fully developed turbulent air flow, heat transfer and friction characteristics of ducts with rib turbulators on two opposite wall of the square and rectangular ducts have been extensively studied, from experimental point of view.

Also the numerical investigations are in a good number and their accuracy has grown with the improvement of calculator computational power and turbulence modelling. Several authors provided numerical studies on the effects of ribs in ducts and channels with air, considering different arrangements, in terms of height, shape and orientation of turbulators [21-26]. Although these approaches have adopted sophisticated turbulence closure models 
that range from two-equation models to large eddy simulations (LES) for the velocity field, a rather simple heat transfer turbulence model based on the Reynolds analogy, that is, heat momentum transport similarity, via a turbulent Prandtl number, is used for the temperature field. Simulations indicated the importance of roughness geometry and pitches on the heat transfer mechanics, with optimal dimensionless spacing in the range 8-14, as underlined by Slanciauskas [27]. Liou et al. [28] performed a comparison between an experimental and a numerical investigation on the heat transfer and the air flow behaviour in a rectangular channel with streamwise periodic ribs mounted on one of the principal walls. They concluded that the flow acceleration and turbulence intensity are two major factors influencing the heat transfer coefficient and they found the optimum in terms of heat transfer coefficient enhancement for the pitch to rib height ratio equal to 10. Rau et al. [29] experimentally confirmed optimum pitch to rib height ratio equal to 9 . Hence, their investigation reveal that not only the rib geometry but also its geometry arrangement play a vital role in enhancing the heat transfer coefficient, as pointed out by Wang and Sundén [30]. They underlined that the local heat transfer was strongly dependent on the rib shape, for example regarding the region just downstream the rib. However, their results are in contrast with the results provided by Ahn [31] who evaluated the best heat transfer performances for the triangular-shaped ribs studied, in fully developed regime. Several turbulence models and their improvements have been recently proposed. Ryu et al. [32,33] solved the Reynolds-averaged NavierStokes equations, coupled with the $k-\omega$ turbulence model with near-wall treatment, by a finite-volume method. They studied both the thermal and fluid-dynamic behaviours of turbulent flows with two-dimensional ribs and three-dimensional blocks in the context of rough surfaces. Elements were square, triangular, semicircular and wavy wall-shaped ribs with a dimensionless height equal to 0.1, finding that the maximum resistance occurs at pitch to height ratio below 10. Chaube et al. [34] confirmed the good matching between the predictions by SST $k-\omega$ turbulent model and experimental results and they underlined the significant enhancement of the heat transfer in comparison to that for a smooth surface even for small Reynolds numbers.

This work extends the investigation carried out in [35] about a two-dimensional channel with differently shaped ribs. In particular, the working fluid is water instead of air because a few literature data has been carried out at this time. The ribs are obtained on the principal walls, heated by a constant uniform heat flux. The main aim of the present analysis is to analyze the flow and the heat transfer characteristics of the ribbed channel by means of Fluent code v6.3 [36]. The ribs are provided on the heated walls. A large amount of friction and heat transfer data, for different values of the dimensionless pitch and height with square, rectangular, trapezoidal and triangular shape ribs, has been generated for Reynolds numbers in the range between 20000 and 60000 .

\section{Governing Equations}

A computational fluid-dynamic analysis of a two-dimensional channel model, provided with differently shaped ribs, as reported in Figure 1, is considered in order to evaluate its thermal and fluid-dynamic behaviours and study the temperature and velocity fields. A constant uniform heat flux is applied on the external channel walls. Different inlet velocities are considered in the ranges of turbulent regime and the working fluid is water with constant properties. 


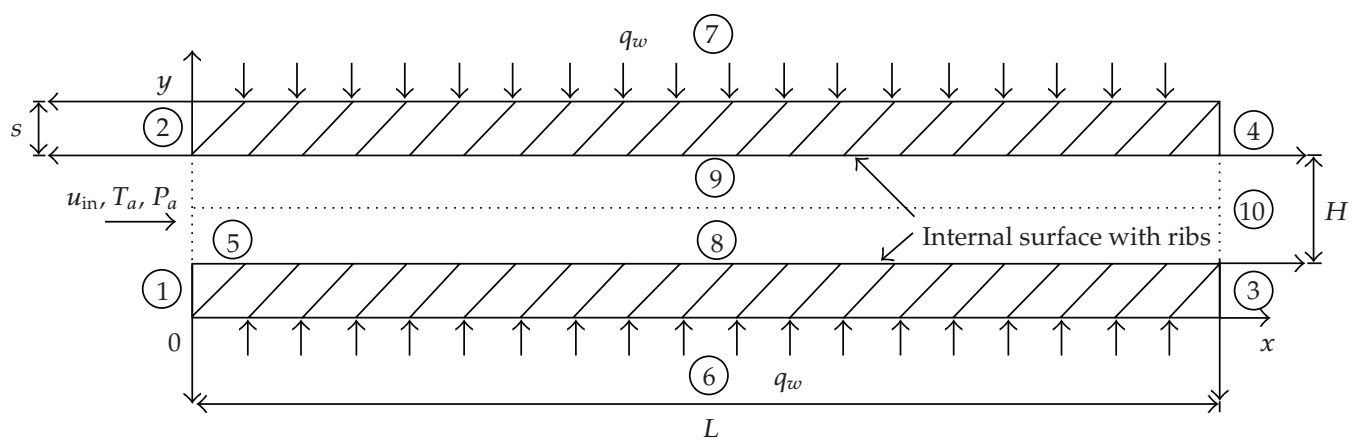

(a)

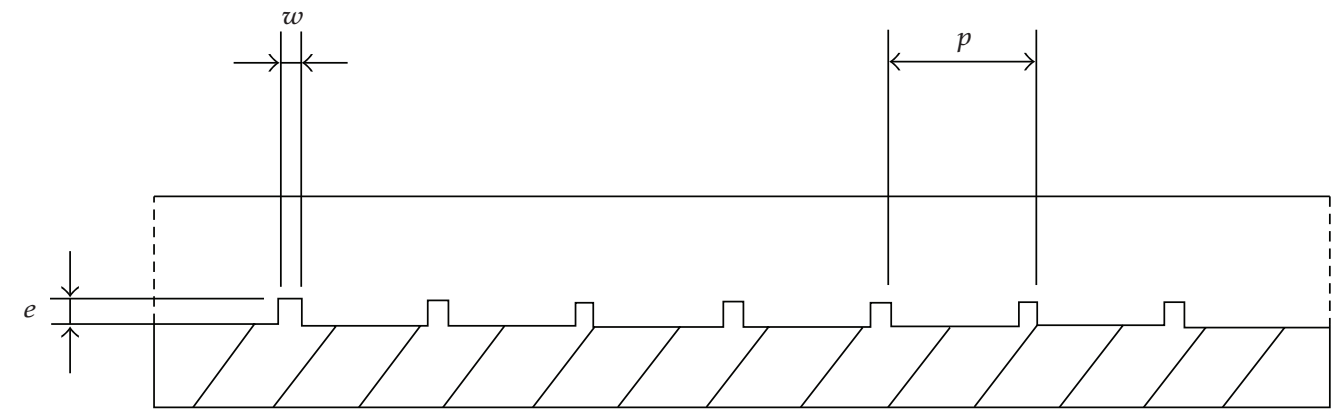

(b)

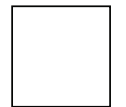

1

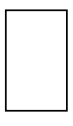

2

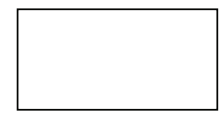

3

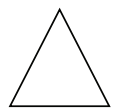

4

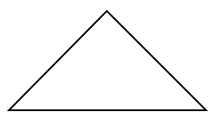

5

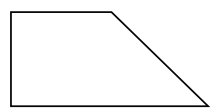

6

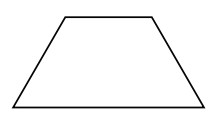

7

(c)

Figure 1: Sketch of the model: (a) geometrical model, (b) characteristic rib parameters, and (c) shapes of the considered ribs-(1) square-rib, (2) rectangular rib with $w / e=0.5$, (3) rectangular rib with $w / e=2.0$, (4) triangular rib with $w / e=1.0$, (5) triangular rib with $w / e=2.0$, (6) rectangular trapezoidal rib with $w / e=2.0$, and (7) isosceles trapezoidal rib with $w / e=2.0$.

Governing equations of continuity, momentum and energy are solved for a steady state turbulent flow in rectangular coordinates, under the hypotheses of steady state, twodimensional, incompressible, turbulent, constant properties flow conditions:

Continuity: $\frac{\partial}{\partial x_{i}}\left(\rho u_{i}\right)=0$,

Momentum: $\frac{\partial}{\partial x_{j}}\left(\rho u_{i} u_{j}\right)=-\frac{\partial P}{\partial x_{i}}+\frac{\partial}{\partial x_{j}}\left[\mu\left(\frac{\partial u_{i}}{\partial x_{j}}+\frac{\partial u_{j}}{\partial x_{i}}-\frac{2}{3} \delta_{i j} \frac{\partial u_{i}}{\partial x_{j}}\right)\right]+\frac{\partial}{\partial x_{j}}\left(-\rho \overline{u_{i}^{\prime} u_{j}^{\prime}}\right)$,

Energy: $\frac{\partial}{\partial x_{i}}\left[u_{i}(\rho E+p)\right]=\frac{\partial}{\partial x_{j}}\left[\left(\lambda+\frac{c_{p} \mu_{t}}{P r_{t}}\right) \frac{\partial T}{\partial x_{j}}+u_{i}\left(\tau_{i j}\right)_{\mathrm{eff}}\right]$, 
where $E$ is the total energy, $E=c_{p} T-p / \rho+u^{2} / 2$, and $\left(\tau_{i j}\right)_{\text {eff }}$ is the deviatoric stress tensor, defined as

$$
\left(\tau_{i j}\right)_{\mathrm{eff}}=\mu_{\mathrm{eff}}\left(\frac{\partial u_{j}}{\partial x_{i}}+\frac{\partial u_{i}}{\partial x_{j}}\right)-\frac{2}{3} \mu_{\mathrm{eff}} \frac{\partial u_{i}}{\partial x_{j}} \delta_{i j}
$$

The Shear-Stress Transport (SST) $k-\omega$ turbulence model has been adopted and its equations are reported below in the form, developed by Menter [37]:

$$
\begin{gathered}
\frac{\partial}{\partial x_{i}}\left(\rho k u_{i}\right)=\frac{\partial}{\partial x_{j}}\left(\Gamma_{k} \frac{\partial k}{\partial x_{j}}\right)+\widetilde{G}_{k}-Y_{k}+S_{k}, \\
\frac{\partial}{\partial x_{i}}\left(\rho \omega k u_{i}\right)=\frac{\partial}{\partial x_{j}}\left(\Gamma_{\omega} \frac{\partial \omega}{\partial x_{j}}\right)+G_{\omega}-Y_{\omega}+D_{w}+S_{\omega},
\end{gathered}
$$

where $G_{k}$ is the production of turbulence kinetic energy due to mean velocity gradients, $G_{\omega}$ represents the generation of $\omega$ :

$$
\tilde{G}_{k}=\min \left(G_{k}, 10 \beta^{*} k \omega\right)
$$

with $G_{k}=-\rho \overline{u_{i}^{\prime} u_{j}^{\prime}}\left(\partial u_{j} / \partial x_{i}\right)$

$$
G_{\omega}=\frac{\alpha}{v_{t}} G_{k}
$$

where $v_{t}$ is the kinematic turbulent viscosity and $\beta^{*}$ a model constant; $\alpha$ is given by

$$
\alpha=\alpha_{\infty} \frac{\left(\alpha_{0}^{*}+\operatorname{Re}_{t} / \mathrm{Re}_{w}\right)}{\left(1+\mathrm{Re}_{t} / \mathrm{Re}_{w}\right)}
$$

where $R_{\omega}=2.95 . \beta_{\imath}=0.072$ and $\alpha$ is represented by

$$
\begin{gathered}
\alpha_{\infty}=F_{1} \alpha_{\infty, 1}+\left(1-F_{1}\right) \alpha_{\infty, 2} \\
\alpha_{\infty, 1}=\frac{\beta_{i, 1}}{\beta_{\infty}^{*}}-\frac{\kappa^{2}}{\sigma_{\omega, 1} \sqrt{\beta_{\infty}^{*}}}, \\
\alpha_{\infty, 1}=\frac{\beta_{i, 2}}{\beta_{\infty}^{*}}-\frac{\kappa^{2}}{\sigma_{\omega, 2} \sqrt{\beta_{\infty}^{*}}},
\end{gathered}
$$


where $\kappa=0.41$. In the High-Reynolds number form, $\alpha=\alpha_{\infty}=1.0 . \Gamma_{k}$ and $\Gamma_{\omega}$ represent the effective diffusivity of $k$ and $\omega$ :

$$
\begin{aligned}
& \Gamma_{k}=\mu+\frac{\mu_{t}}{\sigma_{k}}, \\
& \Gamma_{\omega}=\mu+\frac{\mu_{t}}{\sigma_{\omega}},
\end{aligned}
$$

where $\sigma_{k}$ and $\sigma_{w}$ are the turbulent Prandtl numbers for $k$ and $\omega$, respectively,

$$
\begin{gathered}
\sigma_{k}=\frac{1}{F_{1} / \sigma_{k, 1}+\left(1-F_{1}\right) / \sigma_{k, 2}}, \\
\sigma_{w}=\frac{1}{F_{1} / \sigma_{w, 1}+\left(1-F_{1}\right) / \sigma_{w, 2}},
\end{gathered}
$$

and $\mu_{t}$ is the turbulent viscosity, computed from

$$
\mu_{t}=\alpha^{*} \frac{\rho k}{\omega}
$$

The coefficient $\alpha^{*}$ dampens the turbulent viscosity. It is given by

$$
\alpha^{*}=\alpha_{\infty}^{*} \frac{\left(\alpha_{0}^{*}+\operatorname{Re}_{t} / \operatorname{Re}_{k}\right)}{\left(1+\operatorname{Re}_{t} / \operatorname{Re}_{k}\right)},
$$

where $\operatorname{Re}_{t}=\rho k / \mu \omega, R_{k}=6, \alpha_{0}^{*}=\beta_{i} / 3$, and $\beta_{\imath}=0.072$. In the High-Reynolds number form $\alpha^{*}=\alpha_{\infty}^{*}=1.0$. The blending equation $F_{1}$ is given by

$$
\begin{gathered}
F_{1}=\tan \left(\Phi_{1}^{4}\right), \\
\Phi_{1}=\min \left[\max \left(\frac{\sqrt{k}}{0.09 \omega y}, \frac{500 \mu}{\rho y^{2} \omega}\right), \frac{4 \rho k}{\sigma_{w, 2} D_{\omega}^{+} y^{2}}\right] \\
D_{\omega}^{+}=\max \left[2 \rho \frac{1}{\sigma_{\omega, 2}} \frac{1}{\omega} \frac{\partial k}{\partial x_{j}} \frac{\partial w}{\partial x_{j}}, 10^{-10}\right]
\end{gathered}
$$

where $y$ is the distance to the next surface and $D_{\omega}^{+}$is the positive portion of the cross-diffusion term.

$Y_{k}$ and $Y_{\omega}$ represent the dissipation of $k$ and $\omega$ due to turbulence:

$$
\begin{aligned}
& Y_{k}=\rho \beta^{*} k \omega, \\
& Y_{\omega}=\rho \beta \omega^{2},
\end{aligned}
$$


Table 1: Shear stress transport $k-\omega$ model constants.

\begin{tabular}{lllccc}
\hline$\sigma_{\kappa, 1}=1.176$ & $\sigma_{\kappa, 2}=1.0$ & $\sigma_{\omega, 1}=2.0$ & $\sigma_{\omega, 2}=1.168$ & $\alpha_{1}=0.31$ & $\beta_{i, 1}=0.075$ \\
$\beta_{i, 2}=0.0828$ & $\alpha_{\infty}^{*}=1.0$ & $\alpha_{\infty}=0.52$ & $\beta_{\infty}^{*}=0.09$ & $\beta_{i}=0.072$ & $\alpha_{0}=1 / 9$ \\
$R_{\beta}=8.0$ & $R_{\kappa}=6.0$ & $R_{\omega}=2.95$ & $\xi^{*}=1.5$ & $\sigma_{\kappa}=2.0$ & $\sigma_{\omega}=2.0$ \\
\hline
\end{tabular}

with $\beta$ and $\beta^{*}$ are model constants; moreover

$$
\beta_{i}=F_{1} \beta_{i, 1}+\left(1-F_{1}\right) \beta_{i, 2}
$$

$D_{\omega}$ represents the cross-diffusion term while $S_{k}$ and $S_{\omega}$ are possible source terms. In particular, $D_{\omega}$ is given by

$$
D_{\omega}=2\left(1-F_{1}\right) \rho \sigma_{\omega, 2} \frac{1}{\omega} \frac{\partial k}{\partial x_{j}} \frac{\partial \omega}{\partial x_{j}}
$$

The model constants are summarized in Table 1. A two-dimensional conduction model in heated walls is employed and the equation in the steady-state regime is

$$
\frac{\partial}{\partial x_{j}}\left(\lambda \frac{\partial T}{\partial x_{j}}\right)=0
$$

The working fluid is water and the assigned boundary conditions are the following:

(i) inlet section: uniform velocity and temperature profile,

(ii) outlet section: outflow,

(iii) duct walls: velocity components equal to zero,

(iv) external duct walls: uniform heat flux.

\section{Geometrical Configuration}

The two-dimensional model, depicted in Figure 1, represents a channel with a length, $L$, equal to $250 \mathrm{~mm}$ while its height $H$ is set equal to $10 \mathrm{~mm}$ and width $W$ is $1000 \mathrm{~mm}$; the hydraulic diameter is equal to $20.0 \mathrm{~mm}$. The $3 \mathrm{~mm}$ thick wall is made up by aluminium and a constant heat flux equal to $10 \mathrm{~kW} / \mathrm{m}^{2}$ has been applied on the external surfaces. Square, rectangular, triangular and trapezoidal ribs are mounted on the internal principal walls and they are characterized by different geometry ratios as depicted in Figures $1(b)$ and $1(c)$. The roughness parameters are determined by the height $(e)$, pitch $(p)$ width $(w)$ and shape of turbulators. These parameters identify the families of geometrically similar roughness and they can be expressed in the form of the following dimensionless parameters:

(i) relative roughness pitch, $p / e$,

(ii) relative roughness height, $e / d$,

(iii) relative roughness width, $w / e$. 
Table 2: Properties of water.

\begin{tabular}{lc}
\hline$\rho\left(\mathrm{kg} / \mathrm{m}^{3}\right)$ & 997 \\
$c_{p}(\mathrm{~J} / \mathrm{kg} \mathrm{K})$ & 4177 \\
$\mu(\mathrm{Pa} \mathrm{s})$ & $845 e-6$ \\
$\lambda(\mathrm{W} / \mathrm{m} \mathrm{K})$ & 0.610 \\
\hline
\end{tabular}

In this paper, square-ribs, rectangular ribs $(w / e=0.5$ and 2.0$)$, triangular ribs $(w / e=$ 1.0 and 2.0) and trapezoidal ribs (isosceles and rectangular trapezium with $w / e=2.0$ ) are considered. The range of dimensionless roughness parameters and Reynolds numbers employed in this investigation are given below:

(i) reynolds number, Re (from 20000 to 60000),

(ii) dimensionless roughness pitch, $p / e$ (from 4 to 20),

(iii) dimensionless height, $e / d(0.02$ and 0.05$)$.

The dimensionless parameters, here considered, are

$$
\begin{gathered}
\operatorname{Re}=\frac{u_{\mathrm{av}} d}{v}, \\
\mathrm{Nu}_{\mathrm{av}}=\frac{\dot{q} d}{\left(T_{w}-T_{m}\right) \lambda_{f}},
\end{gathered}
$$

where $T_{w}$ and $T_{m}$ represent the average wall temperature and the average bulk temperature, respectively.

$$
f=2 \frac{\Delta P d}{L} \frac{1}{\rho u_{\mathrm{av}}^{2}}
$$

\section{Numerical Model}

The governing equations are solved by means of the finite volume method. The working fluid is water and its properties are considered constant. In Table 2 the values of density, specific heat, thermal conductivity and dynamic viscosity, obtained by Rohsenow et al. [38], are given. A steady-state solution and a segregrated method are chosen to solve the governing equations, which are linearized implicitly with respect to dependent variables of the equation. A second-order upwind scheme is chosen for energy and momentum equations. The SIMPLE coupling scheme is chosen to couple pressure and velocity. The convergence criteria of $10^{-5}$ and $10^{-8}$ are assumed for the residuals of the velocity components and energy, respectively. It is assumed that the incoming flow is turbulent at ambient temperature, $T_{a}=293 \mathrm{~K}$, and pressure. Different inlet uniform velocities, $u_{\mathrm{in}}$, equal to $0.85,1.28,1.70$, 2.13 and $2.56 \mathrm{~m} / \mathrm{s}$, corresponding to Reynolds numbers ranging from 20000 to 60000, were considered. Furthermore, the inlet turbulence intensity value is set to $1 \%$. Along the solid walls no slip condition is employed whereas a velocity inlet and outflow conditions are given for the inlet and outlet surfaces. The boundary conditions in the mathematical forms are given in Table 3 and the initial conditions for temperature and velocity are $T_{a}$ and $u_{\text {in }}$, respectively. 
Table 3: Boundary conditions.

\begin{tabular}{lccc}
\hline Wall & $u_{i}$ & $u_{j}$ & $T$ \\
\hline $1,2,3,4$ & & & $\partial T_{\mathrm{sl}} / \partial x=0$ \\
5 & $u_{i}=u_{i n}$ & $u_{j}=0$ & $T_{f}=T_{a}$ \\
6 & & & $-\lambda_{\mathrm{sl}}\left(\partial T_{\mathrm{sl}} / \partial y\right)=q_{w}$ \\
7 & & $\lambda_{\mathrm{sl}}\left(\partial T_{\mathrm{sl}} / \partial y\right)=\dot{q}_{w}$ \\
8,9 & $u_{i}=0$ & $u_{j}=0$ & $T_{f}=T_{\mathrm{sl}}$ \\
& & & $\lambda_{\mathrm{sl}}\left(\partial T_{\mathrm{sl}} / \partial y\right)=\lambda_{f}\left(\partial T_{f} / \partial y\right)$ \\
10 & $\partial u_{i} / \partial x=0$ & $\partial u_{j} / \partial x=0$ & $\partial T_{f} / \partial x=0$ \\
\hline
\end{tabular}

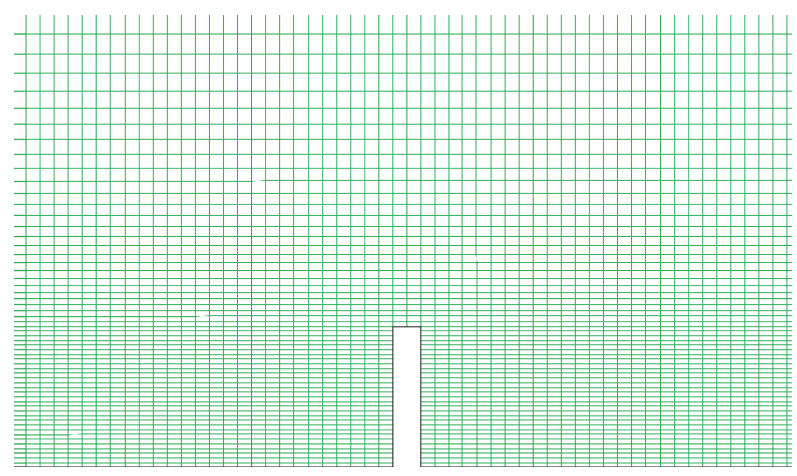

Figure 2: Scheme of the adopted mesh into the channel.

Four different grid distributions are tested, to ensure that the numerical results were grid independent for the channel with rectangular ribs, with $p / e=20, e / d=0.05$, and $w / e=0.5$. They have 27000, 55400, 108100, 189900 and 385000 nodes, respectively. The grid mesh is structured in each case and optimized taking into account the grid adoption for $y^{+}=1$ at adjacent wall region. The sketch of the chosen grid distribution is reported in Figure 2. The third grid case has been adopted because it ensured a good compromise between the machine computational time and the accuracy requirements. In fact, comparing the third and fourth mesh configurations, in terms of wall average temperature, mass-weighted average outlet temperature, average outlet velocity and pressure drops, the corresponding percentage relative errors are $0.9 \%, 0.3 \%$ and $1.5 \%$, respectively.

Results are validated by comparing the obtained numerical data with the literature ones in terms of average Nusselt numbers and friction coefficients, in the case of smooth channel and ribbed one $[3,22,39]$. For the smooth channel the following correlations are adopted and the comparison is depicted in Figure 3.

$$
\text { Dittus-Boelter correlation: } \mathrm{Nu}_{s}=0.024 \operatorname{Re}_{d}^{0.8} \operatorname{Pr}^{0.4}
$$




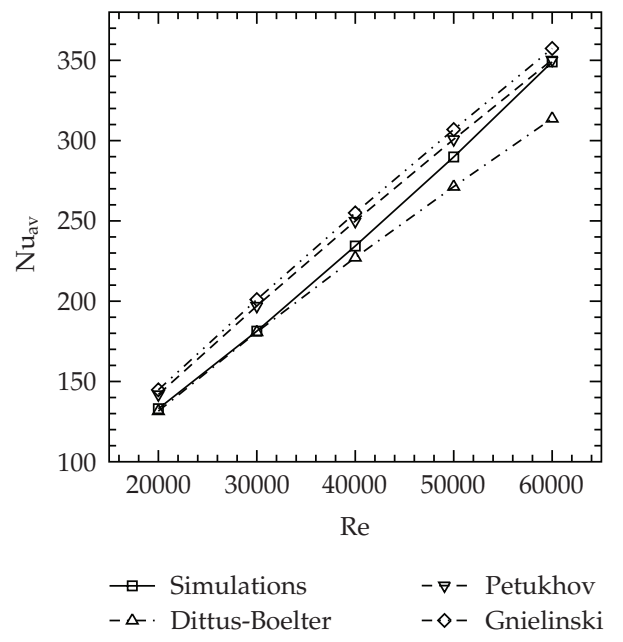

(a)

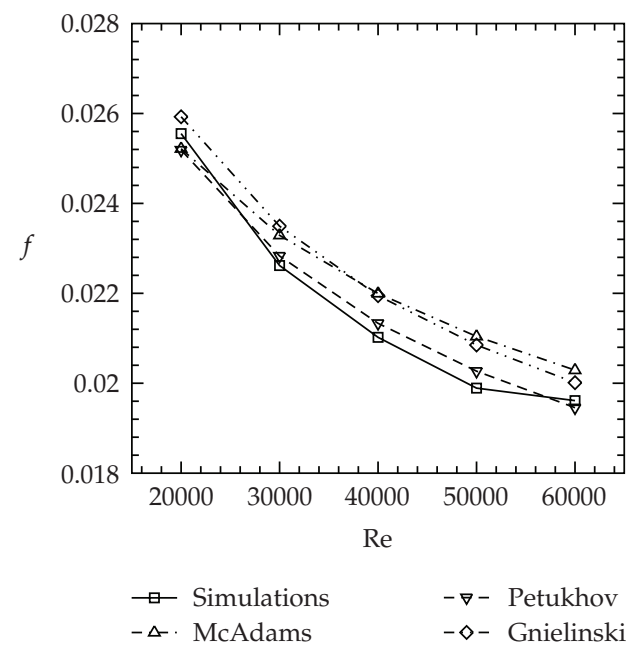

(b)

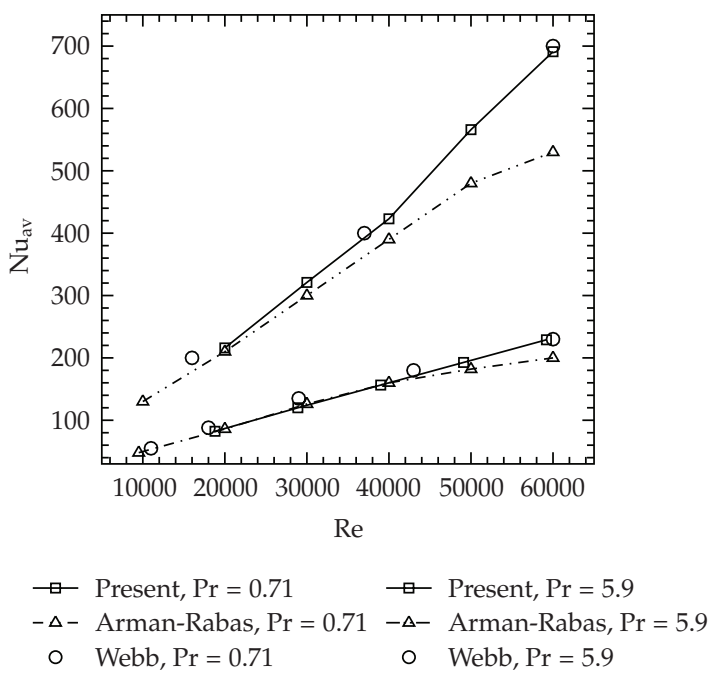

(c)

Figure 3: Validation of results: (a) average Nusselt number, smooth channel, (b) friction factor, smooth channel, and (c) average Nusselt number, ribbed channel (rectangular ribs, $w / e=0.5, e / d=0.02$, and $p / e=20)$.

for $0.5<\operatorname{Pr}<120,6.0 \times 10^{3}<\operatorname{Re}_{d}<1.0 \times 10^{7} ; 60<(L / d)$

$$
\text { Petukhov correlation: } \mathrm{Nu}_{s}=\frac{\operatorname{Re}_{d} \operatorname{Pr} f / 8}{1.07+12.7(f / 8)^{1 / 2}\left(\operatorname{Pr}^{2 / 3}-1\right)}
$$

with $f_{s}=\left(1.84 \log _{10} \operatorname{Re}_{d}-1.64\right)^{-2}$ for $0.5<\operatorname{Pr}<200,1.0 \times 10^{4}<\operatorname{Re}_{d}<5.0 \times 10^{6}$;

$$
\text { Gnielinski correlation: } \mathrm{Nu}_{s}=\frac{f / 8\left(\operatorname{Re}_{d}-1000\right) \operatorname{Pr}}{1+12.7(f / 8)^{1 / 2}\left(\operatorname{Pr}^{2 / 3}-1\right)}
$$


with $f_{s}=\left(0.79 \log _{10} \operatorname{Re}_{d}-1.64\right)^{-2}$ for $0.5<\operatorname{Pr}<200,1.0 \times 10^{4}<\operatorname{Re}_{d}<5.0 \times 10^{6}$;

$$
\text { McAdams correlation: } f_{s}=0.184 \operatorname{Re}_{d}^{-0.2}
$$

for $2.0 \times 10^{4}<\operatorname{Re}_{d}<3.0 \times 10^{5}$.

There is a very good correspondence with the given correlations in terms of average Nusselt number, as reported in Figure 3(a) while Figure 3(b) shows the little percentage error in terms of friction factor and a good fitting with the experimental curves. A difference of $5 \%$ at most has been calculated by comparing results with ones for Gnielinski correlation. The comparison with experimental and numerical data available for water forced convection in a ribbed channel $[3,22]$ with rectangular turbulators $(e / d=0.02, p / e=20$, and $w / e=0.5)$ is reported. The present results, shown in Figure 3(c), fit very well with the experimental data and improve the accuracy in comparison with the previous numerical approach.

\section{Results and Discussion}

Results are presented in form of graphs depicting the average Nusselt number, friction factors and required pumping power at different dimensionless pitches, heights and ribs shapes, and Reynolds numbers, and also temperature fields and streamlines contours for some significant cases are given. Ribs are characterized by square, rectangular, trapezoidal and triangular shapes with different values of $w / e$ ratio.

Figure 4 presents the profiles of the ratio $\mathrm{Nu}_{\mathrm{av}} / \mathrm{Nu}_{\mathrm{av}, \mathrm{s}}$ in order to describe the heat transfer rate improvement of the ribbed configuration compared to the smooth channel. Results are reported as a function of $p / e$ ratio for square, rectangular, triangular and trapezoidal ribs, with $e / d$ equal to 0.05 at $\operatorname{Re}=20000,30000$, and 60000. In Figure 4(a), it is observed that the profile for square-ribs increases from the lowest values of $p / e$, attaining the maximum value at the dimensionless pitch of 8 ; then, it decreases for further increases in the pitch values. This behaviour may be noticed for all the considered Reynolds numbers; moreover, $\mathrm{Nu}_{\mathrm{av}} / \mathrm{Nu}_{\mathrm{av}, s}$ ratio tends to increase as Re increases. In fact, $\mathrm{Nu}_{\mathrm{av}} / \mathrm{Nu}_{\mathrm{av}, s}=1.97$, $2.03,2.05$ at $p / e=8$ for $\operatorname{Re}=20000,30000$, and 60000, respectively. Figure $4(\mathrm{~b})$ is referred to the rectangular ribs and it shows that the shape with $w / e=0.5$ is characterized by more significant thermal performances compared to the elements with $w / e=2.0$. The maximum values are attained at $p / e=10$. The triangular ribs exhibit the highest thermal performances. Maxima are observed for $p / e=6$, where $\mathrm{Nu}_{\mathrm{av}} / \mathrm{Nu}_{\mathrm{av}, s}=2.60$ and 2.58 at $\mathrm{Re}=60000$, for $w / e=2.0$ and 1.0, respectively. Lower Nusselt number augmentation ratios are detected for the trapezoidal ribs, which show the maximum values at $p / e=10$, like the rectangular ones but the thermal performances are slightly improved. For all the considered configurations, although the rib-surface area increases, the heat transfer rate does not grow in such evident way; this result suggests that the primary cause for the enhancement is the strong turbulent motion induced by the ribs.

$\mathrm{Nu}_{\mathrm{av}} / \mathrm{Nu}_{\mathrm{av}, \mathrm{s}}$ ratio decreases by reducing the height of the rough elements, as reported in Figure 5. In fact, for $e / d=0.02$, an average reduction of $20-25 \%$, in terms of average Nusselt number, is observed at $\operatorname{Re}=40000$. Maxima are attained at the same values of dimensionless pitch, previously reported. For example, at $p / e=10 \mathrm{Nu}_{\mathrm{av}} / \mathrm{Nu}_{\mathrm{av}, \mathrm{s}}=1.62$ and 2.07 , for the rect trapezoidal turbulators, at $e / d=0.02$ and 0.05 , respectively.

The highest values of the average Nusselt number are exhibited for slightly lower pitches, in comparison with the results for air as working fluid, reported in [35] while the 


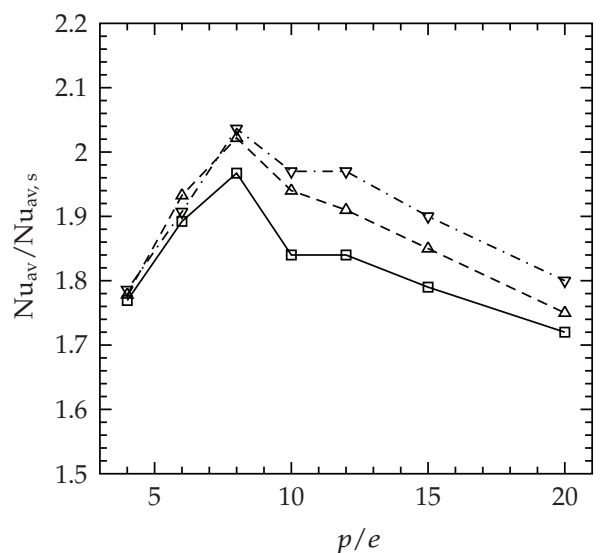

Square ribs $e / d=0.05$

$\rightarrow \operatorname{Re}=20000$

$-\Delta-\operatorname{Re}=30000$

$\rightarrow-\operatorname{Re}=60000$

(a)

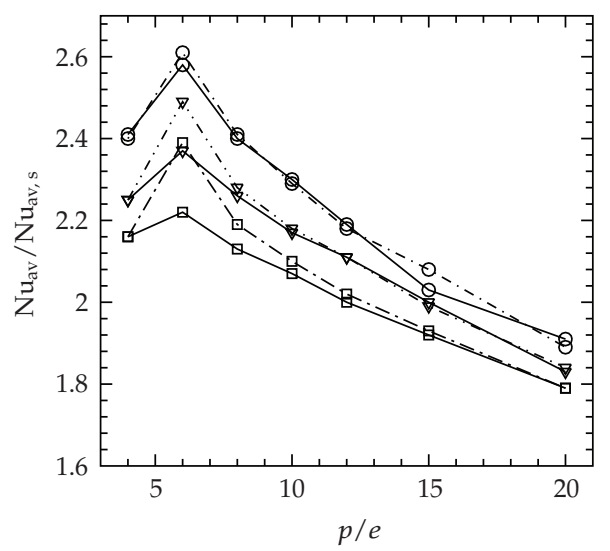

Triangular ribs $e / d=0.05$

$$
\begin{aligned}
& \square w / e=1 \\
& \square-\operatorname{Re}=20000 \\
& \rightarrow-\operatorname{Re}=30000 \\
& -\quad \operatorname{Re}=60000
\end{aligned}
$$

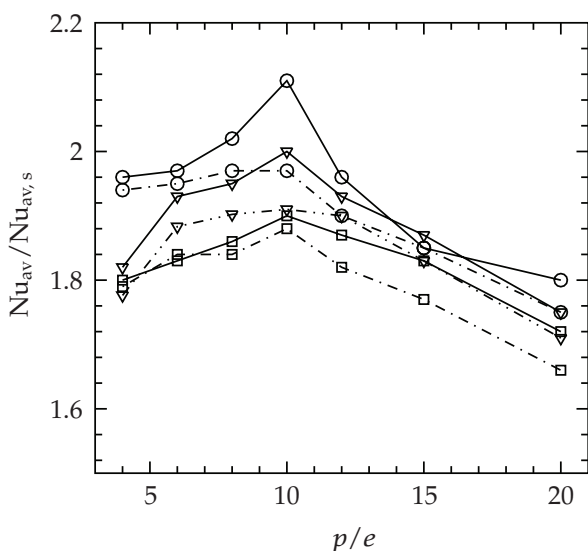

Rectangular ribs $e / d=0.05$

$$
\begin{aligned}
& \text { - } w / e=0.5 \\
& \square \operatorname{Re}=20000 \\
& \text {-. } w / e=2 \\
& \rightarrow \operatorname{Re}=30000 \\
& \neg-\operatorname{Re}=20000 \\
& \bigcirc \operatorname{Re}=60000 \\
& -\nabla-\operatorname{Re}=30000
\end{aligned}
$$

(b)

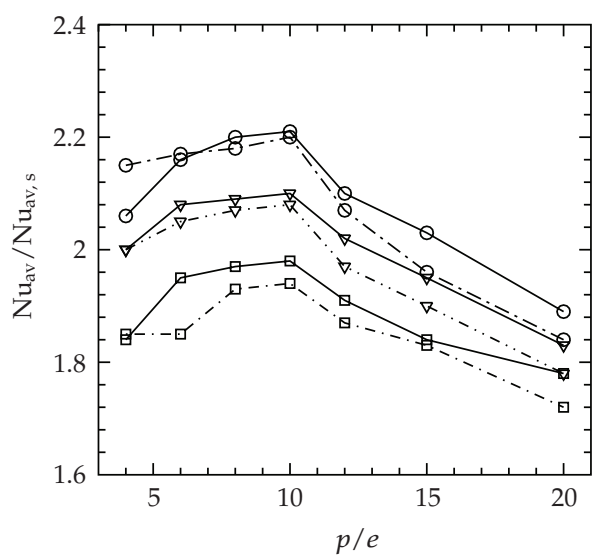

Trapezoidal ribs $e / d=0.05$

$$
\begin{aligned}
& \text { - Iso ..- Rect } \\
& \square-\operatorname{Re}=20000 \quad-\square-\operatorname{Re}=20000 \\
& \rightarrow-R e=30000 \quad-\nabla-\operatorname{Re}=30000 \\
& \bigcirc-\operatorname{Re}=60000 \quad \bigcirc-\operatorname{Re}=60000
\end{aligned}
$$

(d)

Figure 4: Average Nusselt number profiles, referred to the smooth channel results, as a function of $p / e$ at $\operatorname{Re}=20000,30000$, and 60000, for $e / d=0.05$ : (a) square-ribs, (b) rectangular ribs with $w / e=0.5$ and 2.0, (c) triangular ribs with $w / e=1.0$ and 2.0, and (d) isosceles and rectangular trapezoidal ribs with $w / e=2.0$.

results in terms of friction factor are confirmed, as depicted in Figure 6, which shows the results in terms of friction factor as a function of $p / e$ at $\operatorname{Re}=20000,30000$, and 60000, and $e / d$ equal to 0.05 for different shapes. The square turbulators show in Figure 6(a) that for $p / e<10$ the friction coefficient ratio, referred to the smooth channel, increases rapidly as relative roughness pitch augments; $f$ factor reaches for the maximum value at $p / e=10$ and 


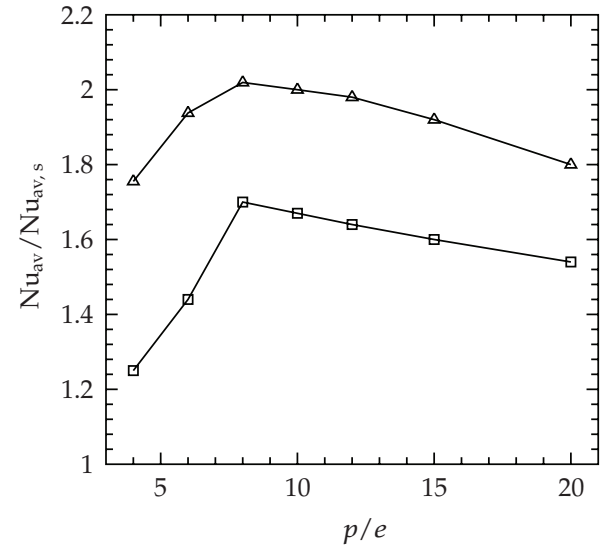

Square ribs $\operatorname{Re}=40000$

$\square-e / d=0.02$

$\triangle e / d=0.05$

(a)

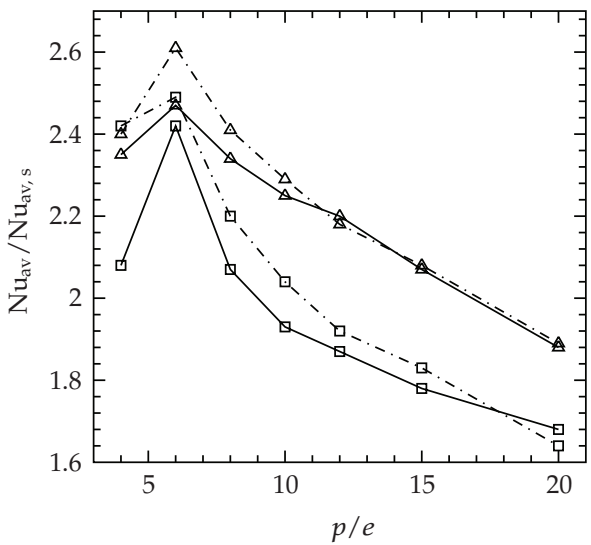

Triangular ribs $\operatorname{Re}=40000$

$\begin{aligned} \square-w / e & =0.5, e / d=0.02 & -\square \cdot w / e=2, e / d=0.02 \\ \triangle-w / e & =0.5, e / d=0.05 & -\Delta \cdot w / e=2, e / d=0.05\end{aligned}$

(c)

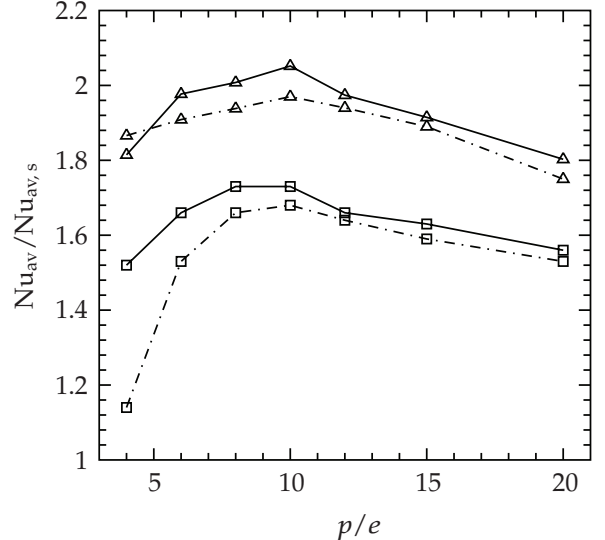

Rectangular ribs $\mathrm{Re}=40000$

$\begin{array}{ll}\square w / e=0.5, e / d=0.02 & -\square \cdot w / e=2, e / d=0.02 \\ \square w / e=0.5, e / d=0.05 & -\checkmark \cdot w / e=2, e / d=0.05\end{array}$

(b)

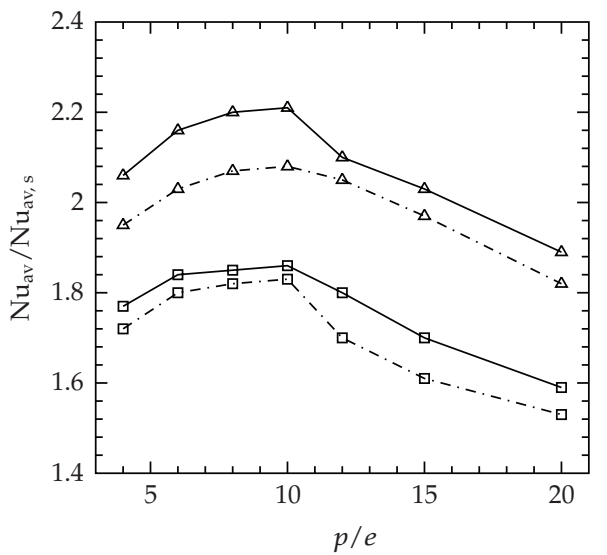

Trapezoidal ribs $\operatorname{Re}=40000$

$\begin{array}{ll}\square \text { Iso, } e / d=0.02 & -\square \cdot \text { Rect, } e / d=0.02 \\ \triangle \text { Iso, } e / d=0.05 & -\Delta \cdot \text { Rect, } e / d=0.05\end{array}$

(d)

Figure 5: Average Nusselt number profiles, referred to the smooth channel results, as a function of $p / e$ at $\operatorname{Re}=40000$, for $e / d=0.02$ and 0.05: (a) square-ribs, (b) rectangular ribs with $w / e=0.5$ and 2.0, (c) triangular ribs with $w / e=1.0$ and 2.0, and (d) isosceles and rectangular trapezoidal ribs with $w / e=2.0$.

a further increase of relative roughness pitch leads to a consequent decrease; this effect is similar to the one observed in rough ducts at high Reynolds numbers. The maximum values are observed for $p / e=10$, for rectangular and trapezoidal ribs, and 8 , for the triangular ones, for all the considered Reynolds numbers. The highest values are obtained for $\mathrm{Re}=$ 60000 in correspondence with the triangular turbulators with the aspect ratio $w / e=1.0$, as depicted in Figure 6(c). In fact, at $\operatorname{Re}=60000 \mathrm{f} / f_{s}=12.8,11.7$ and 11.8, for triangular turbulators with $w / e=1.0$ and 2.0, and rectangular ones with $w / e=0.5$, respectively. The lowest values of friction factor are obtained for the rectangular elements with $w / e=2.0$ and for the trapezoidal ones, as described in Figures 6(b) and 6(d). 


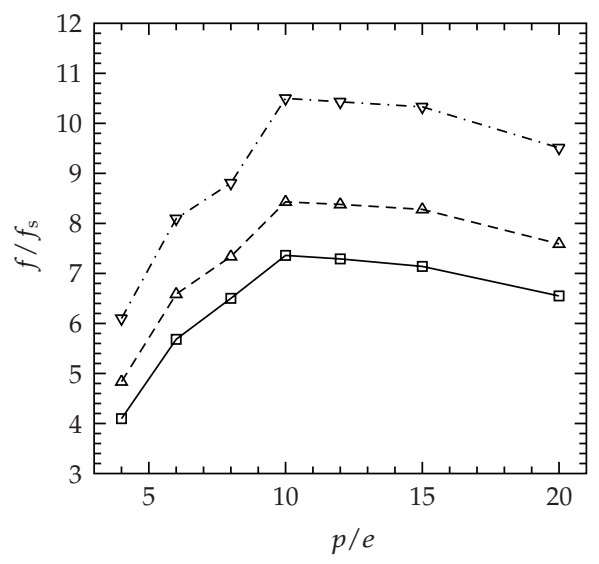

Square ribs $e / d=0.05$

$$
\begin{array}{ll}
\rightarrow- & R e=20000 \\
-\Delta- & R e=30000 \\
-\nabla \cdot & R e=60000
\end{array}
$$

(a)

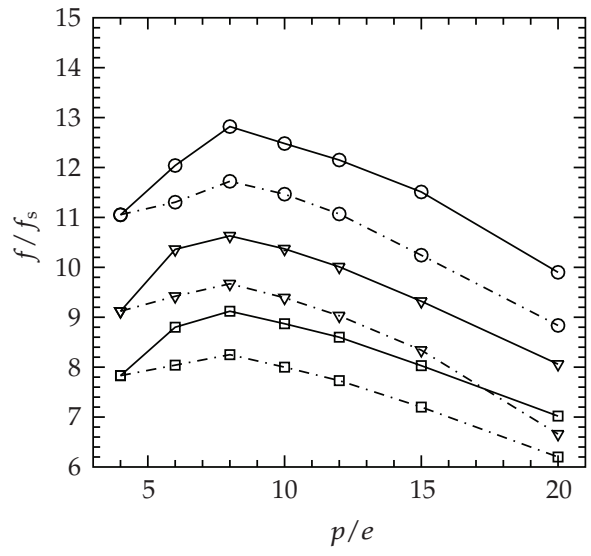

Triangular ribs $e / d=0.05$

$$
\begin{aligned}
& \text { - } w / e=1 \\
& \square-\operatorname{Re}=20000 \\
& \rightarrow \quad \operatorname{Re}=30000 \\
& \multimap \operatorname{Re}=60000 \\
& \begin{array}{ll}
-\cdot- & w / e=2 \\
-\square \cdot & \operatorname{Re}=20000 \\
-\nabla \cdot & \operatorname{Re}=30000 \\
-\odot \cdot & \operatorname{Re}=60000
\end{array}
\end{aligned}
$$

(c)

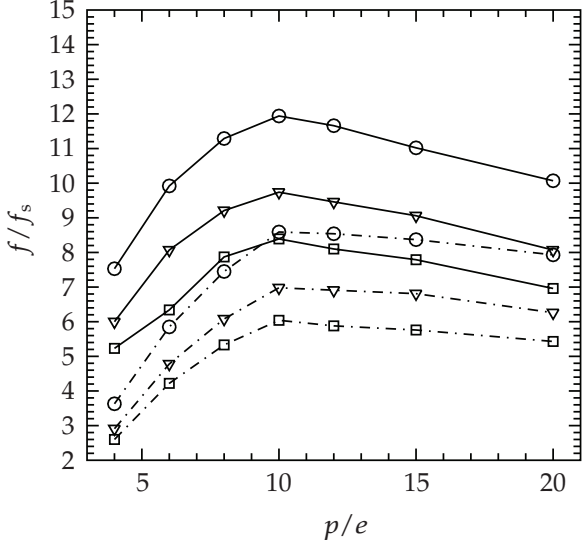

Rectangular ribs $e / d=0.05$

$$
\begin{array}{lll}
-w / e=0.5 & - & w / e=2 \\
\square-\operatorname{Re}=20000 & -\square \cdot & \operatorname{Re}=20000 \\
\rightarrow-\operatorname{Re}=30000 & -\nabla \cdot & \operatorname{Re}=30000 \\
\square-\operatorname{Re}=60000 & -\odot \cdot \operatorname{Re}=60000
\end{array}
$$

(b)

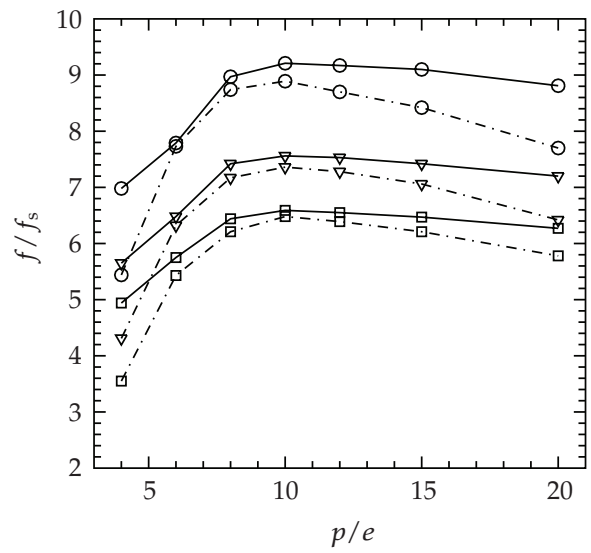

Trapezoidal ribs $e / d=0.05$

$$
\begin{aligned}
& \text { - Iso } \\
& \square \quad \operatorname{Re}=20000 \\
& \rightarrow \quad \operatorname{Re}=30000 \\
& \text {-. . Rect } \\
& \text { - ㅁ. } \quad \operatorname{Re}=20000 \\
& \text { - } \nabla \cdot \quad \operatorname{Re}=30000 \\
& \multimap \operatorname{Re}=60000 \\
& \text { - } \odot \text {. } R e=60000
\end{aligned}
$$

(d)

Figure 6: Friction factor profiles, referred to the smooth channel results, as a function of $p / e$ at $\operatorname{Re}=20000$, 30000, and 60000, for $e / d=0.05$ : (a) square-ribs, (b) rectangular ribs with $w / e=0.5$ and 2.0, (c) triangular ribs with $w / e=1.0$ and 2.0, and (d) isosceles and rectangular trapezoidal ribs with $w / e=2.0$.

Furthermore, the friction factor, $f$, decreases as dimensionless height reduces and, in fact, at $e / d=0.02, f$ values are 2-3 times lower than ones, obtained for ribs with $e / d 0.05$. This behaviour is described in Figure 7 which is referred to $\operatorname{Re}=40000$. The most significant differences are observed for the rectangular and trapezoidal ribs, as reported in Figures $7(b)$ and $7(\mathrm{~d})$. For example, for the rectangular elements with $w / e=0.5, f / f_{s}$ is equal to 10.8 and 3.8 at most, at $e / d=0.05$ and 0.02 , respectively, while, for the iso trapezoidal ribs, the ratio values are 8.3 and 3.5 at $p / e=10$. 


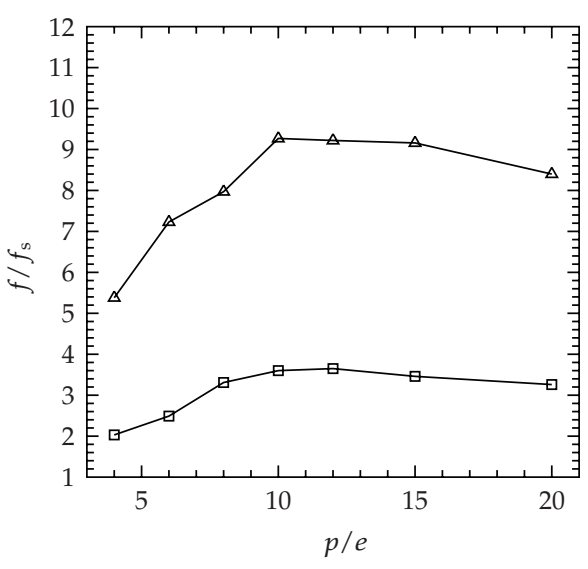

Square ribs $\operatorname{Re}=40000$

$\square e / d=0.02$

$\triangle e / d=0.05$

(a)

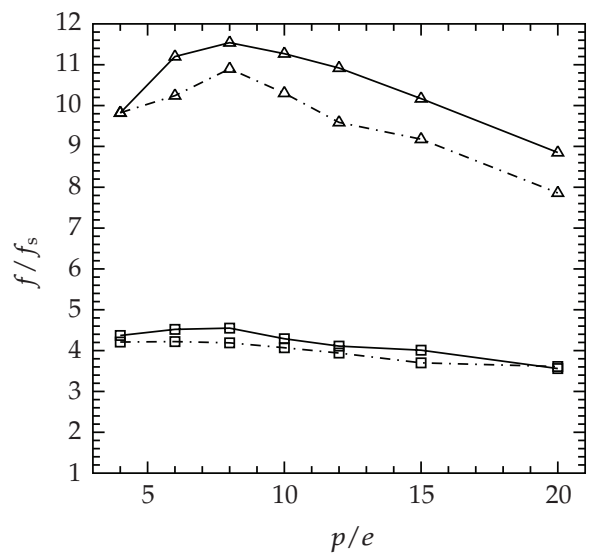

Triangular ribs $\operatorname{Re}=40000$

$\begin{array}{rlrl}\square-w / e & =1, e / d=0.02 & -\square \cdot w / e=2, e / d=0.02 \\ \square w / e=1, e / d=0.05 & -\square \cdot w / e=2, e / d=0.05\end{array}$

(c)

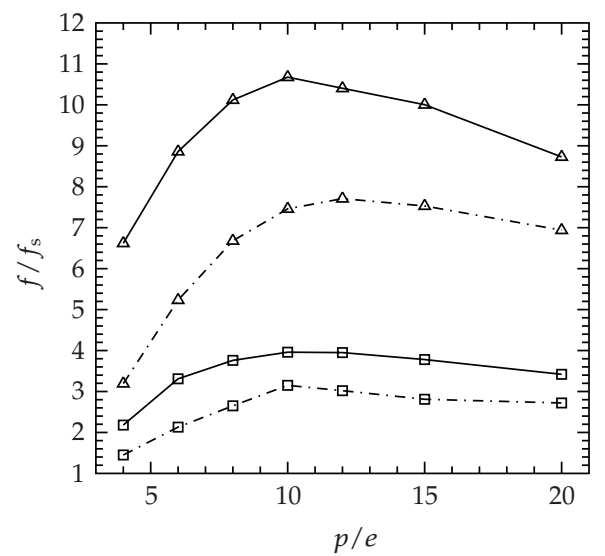

Rectangular ribs $\operatorname{Re}=40000$

$\begin{array}{ll}\square-w / e=0.5, e / d=0.02 & -\square \cdot w / e=2, e / d=0.02 \\ \square w / e=0.5, e / d=0.05 & -\Delta \cdot w / e=2, e / d=0.05\end{array}$

(b)

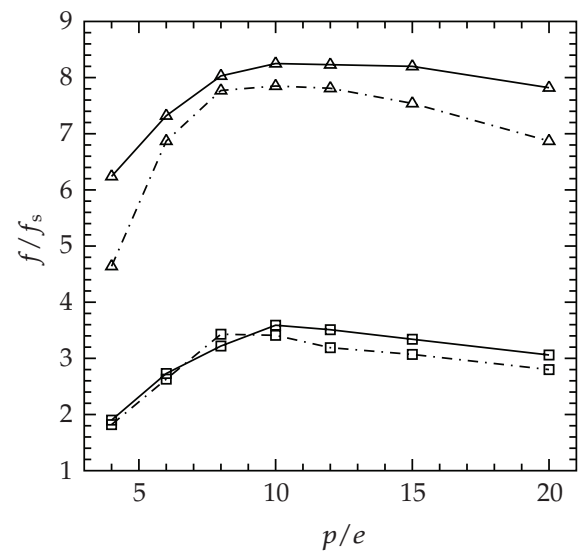

Trapezoidal ribs $\mathrm{Re}=40000$

$\square$ Iso, $e / d=0.02$
$\triangle \quad$ Iso, $e / d=0.05$

- ㅁ. $\cdot$ Rect, $e / d=0.02$

$-\Delta \cdot \operatorname{Rect}, e / d=0.05$

(d)

Figure 7: Friction factor profiles, referred to the smooth channel results, as a function of $p / e$ at $\operatorname{Re}=40000$, for $e / d=0.02$ and 0.05: (a) square-ribs, (b) rectangular ribs with $w / e=0.5$ and 2.0, (c) triangular ribs with $w / e=1.0$ and 2.0, and (d) isosceles and rectangular trapezoidal ribs with $w / e=2.0$.

It is significant to underline that the maximum values of average Nusselt number and friction factor are attained at about the same value of $p / e$ ratio for all the considered Reynolds numbers for each configuration. Moreover, the highest values of friction factor are observed near the values of pitch, where the highest Nusselt numbers are evaluated.

Figure 8 depicts the results in terms of the required pumping power, $\mathrm{PP}$, defined as $u_{\mathrm{av}} A \Delta P$, referred to the smooth channel, at $\operatorname{Re}=40000$, for $e / d=0.02$ and 0.05 and for different shapes of turbulators. The profiles of $\mathrm{PP} / \mathrm{PP}_{s}$ follow the ones, reported in terms of $f / f_{s}$. They confirm that the highest losses are detected for both the considered triangular elements and for the rectangular ones with the aspect ratio $w / e=0.5$, as observed in Figures $8(\mathrm{c})$ and $8(\mathrm{~b})$. Moreover, maxima are attained at the same values of pitch, evaluated for $f / f_{s}$. 


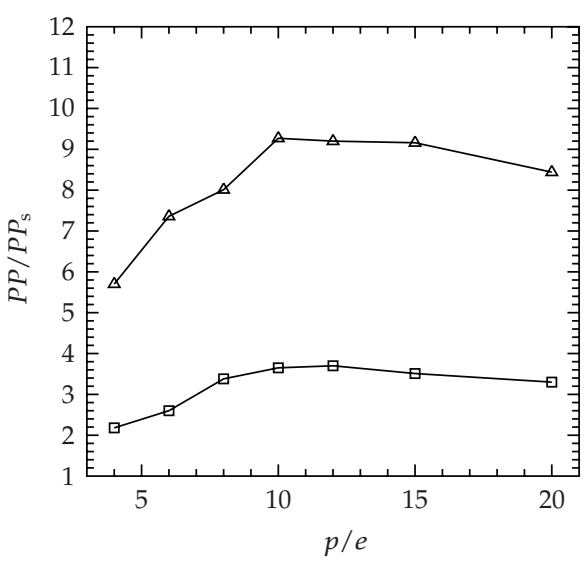

Square ribs $\operatorname{Re}=40000$

$\rightarrow e / d=0.02$

$\triangle e / d=0.05$

(a)

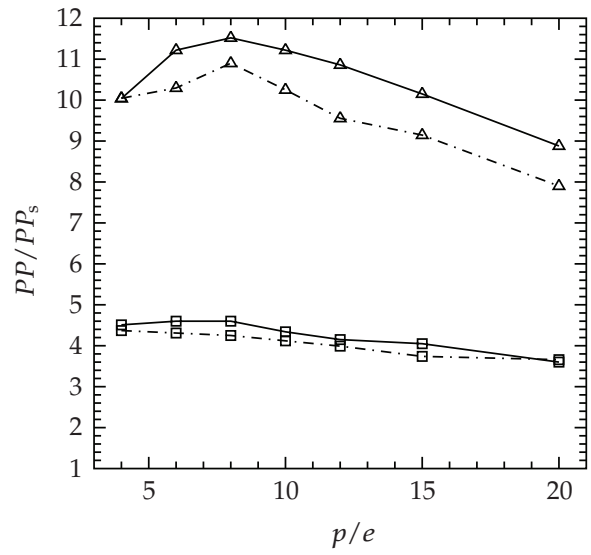

Triangular ribs $\operatorname{Re}=40000$

$\begin{array}{llrl}\rightarrow & w / e=1, e / d=0.02 & -\square \cdot w / e=2, e / d=0.02 \\ \square w / e=1, e / d=0.05 & -\Delta \cdot w / e=2, e / d=0.05\end{array}$

(c)

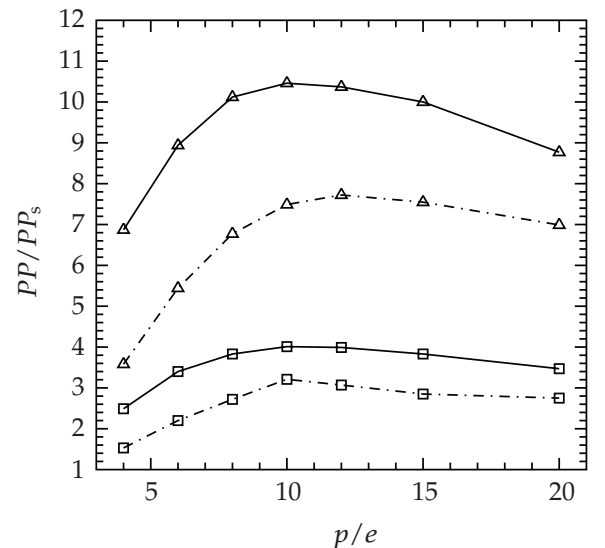

Rectangular ribs $\operatorname{Re}=40000$

$\begin{array}{ll}\square w / e=0.5, e / d=0.02 & -\square \cdot w / e=2, e / d=0.02 \\ \square w / e=0.5, e / d=0.05 & -\Delta \cdot w / e=2, e / d=0.05\end{array}$

(b)

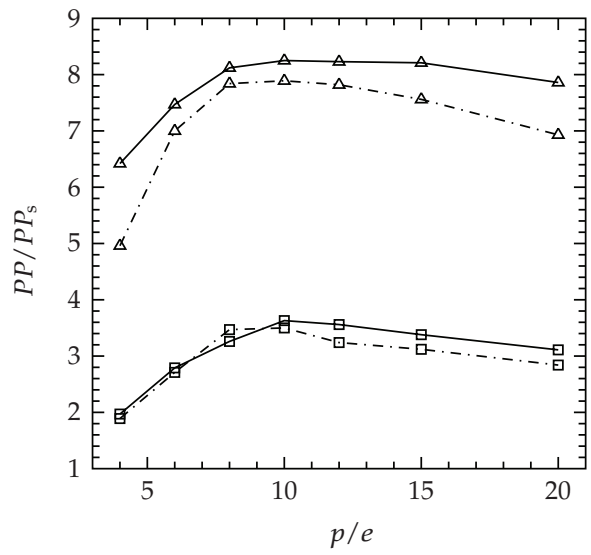

Trapezoidal ribs $\operatorname{Re}=40000$

$\begin{array}{ll}\square \text { Iso, } e / d=0.02 & -\square \cdot \text { Rect, } e / d=0.02 \\ \square \text { Iso, } e / d=0.05 & -\Delta \cdot \text { Rect, } e / d=0.05\end{array}$

(d)

Figure 8: Required pumping power profiles, referred to the smooth channel results, as a function of $p / e$ at $\operatorname{Re}=40000$, for $e / d=0.02$ and 0.05: (a) square-ribs, (b) rectangular ribs with $w / e=0.5$ and 2.0, (c) triangular ribs with $w / e=1.0$ and 2.0, and (d) isosceles and rectangular trapezoidal ribs with $w / e=2.0$.

PEC index is introduced in order to summarize the results and give a method to evaluate and compare the efficiency of different rough elements. As described in [3], it is defined as PEC $=\left(\mathrm{Nu}_{\mathrm{av}} / \mathrm{Nu}_{\mathrm{av}, s}\right) /\left(f / f_{s}\right)^{1 / 3}$. Results in terms of PEC index are reported in Figure 9, for $\operatorname{Re}=40000, e / d=0.02$ and 0.05 , and differently shaped turbulators. Profiles increase as Re decreases as well as $e / d$ values. Maxima are attained near the pitches, where the maximum values of the average Nusselt number are observed, such as at $p / e=6$ for the triangular turbulators and $p / e=8$ for the other configurations. Although the triangular ribs exhibit the most significant losses, they show the highest values of PEC index as well. In fact, PEC is equal to 1.54 at $p / e=6$ and $e / d=0.02$ for the triangular ribs with $w / e=2.0$ while the lowest values are detected for the rectangular ones with $w / e=0.5(\mathrm{PEC}=1.04)$. 


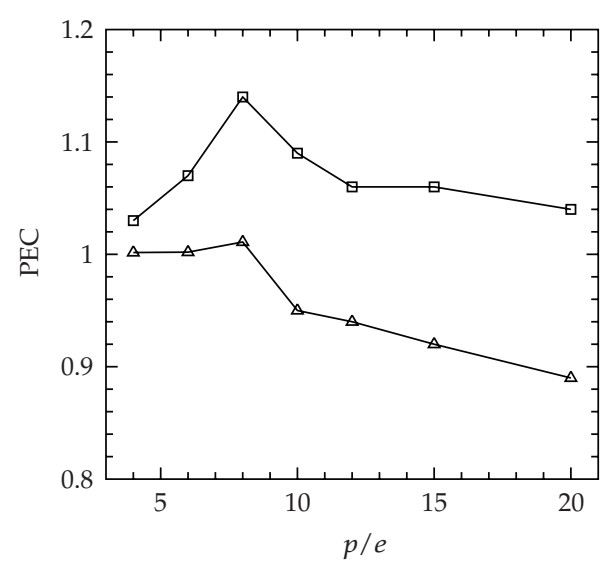

Square ribs $\operatorname{Re}=40000$

$\rightarrow e / d=0.02$

$\triangle e / d=0.05$

(a)

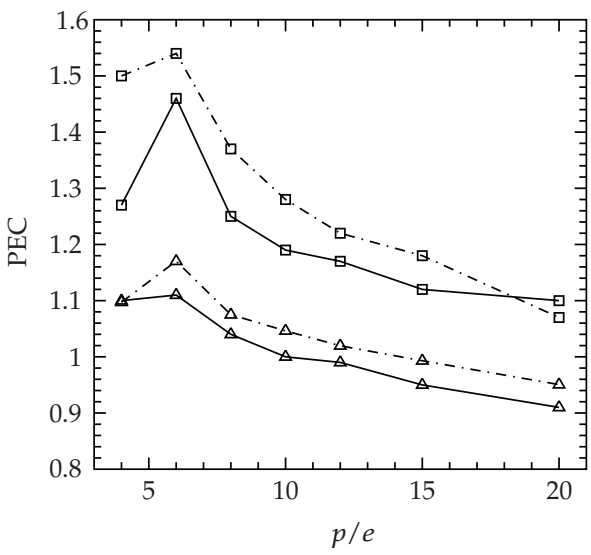

Triangular ribs $\operatorname{Re}=40000$

$\begin{array}{ll}\square w / e=1, e / d=0.02 & -\square \cdot w / e=2, e / d=0.02 \\ \square w / e=1, e / d=0.05 & -\Delta \cdot w / e=2, e / d=0.05\end{array}$

(c)

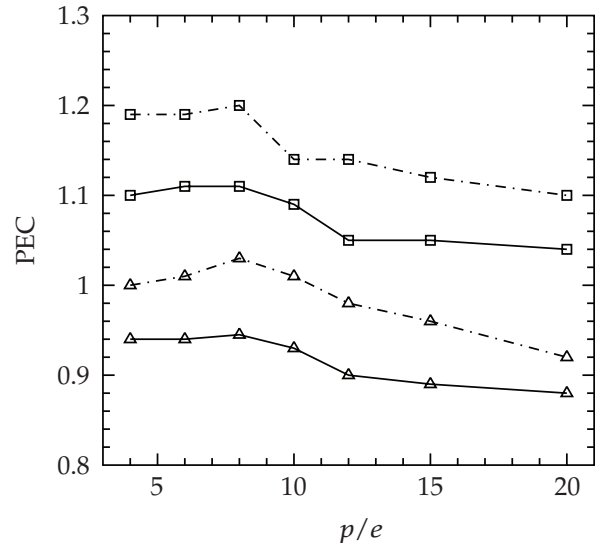

Rectangular ribs $\operatorname{Re}=40000$

$\begin{array}{ll}\square w / e=0.5, e / d=0.02 & -\square \cdot w / e=2, e / d=0.02 \\ \triangle w / e=0.5, e / d=0.05 & -\square \cdot w / e=2, e / d=0.05\end{array}$

(b)

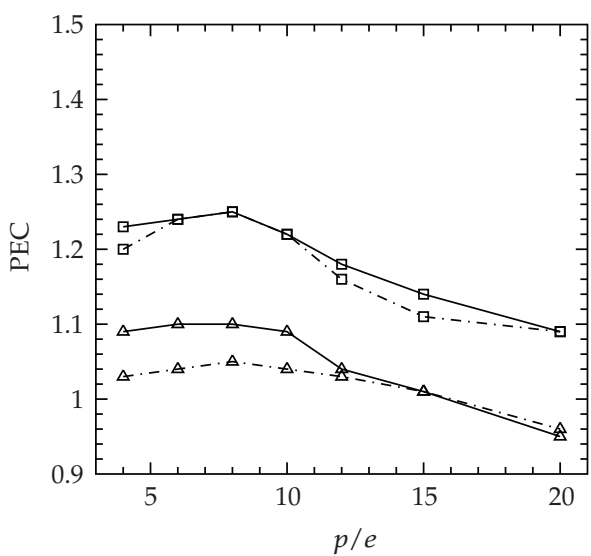

Trapezoidal ribs $\operatorname{Re}=40000$

$\square$ Iso, $e / d=0.02$
$\triangle$ Iso, $e / d=0.05$

- ㅁ. Rect, $e / d=0.02$

$-\Delta \cdot$ Rect, $e / d=0.05$

(d)

Figure 9: PEC index profiles as a function of $p / e$ at $\operatorname{Re}=40000$, for $e / d=0.02$ and 0.05: (a) square-ribs, (b) rectangular ribs with $w / e=0.5$ and 2.0, (c) triangular ribs with $w / e=1.0$ and 2.0, and (d) isosceles and rectangular trapezoidal ribs with $w / e=2.0$.

The dependence on Reynolds number of average Nusselt number and friction factor is presented in Figure 10. Results are given at $e / d=0.05$ in the range of Reynolds numbers from 20000 to 60000 in correspondence with significant $p / e$ ratios. Average Nusselt number grows linearly as Reynolds number increases for all the considered configurations, as shown in Figure 10(a). The most significant thermal behavior is provided by the triangular ribbed channel with $w / e=2.0$ while the lowest average Nusselt numbers are detected for the rectangular ribbed case with $w / e=2.0$. At $\operatorname{Re}=20000$ average Nusselt number is at least 1.8 times greater than the value calculated for the smooth channel while, for the most improved configuration, a growth of about 2.6 times is calculated. In Figure 10(b) it is noticed that at 

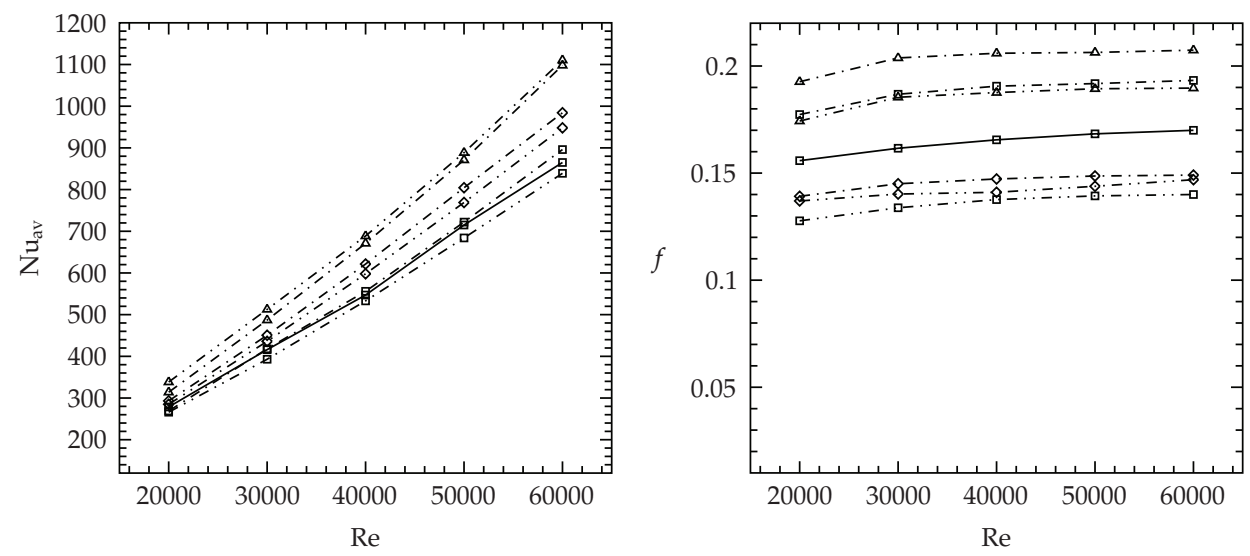

$$
\begin{aligned}
& e / d=0.05 \\
& \square-\text { Square; } p / e=10 \\
& -\square-\text { Rectangular } w / e=0.5 ; p / e=10 \\
& -\square-\text { Rectangular } w / e=2 ; p / e=10 \\
& -\diamond . \text { Trapezoidal iso; } p / e=8 \\
& -\diamond-\text { Trapezoidal rect; } p / e=8 \\
& -\Delta . \quad \text { Triangular } w / e=1 ; p / e=6 \\
& -\Delta-\quad \text { Triangular } w / e=2 ; p / e=6
\end{aligned}
$$

(a)

$$
\begin{aligned}
& e / d=0.05 \\
& \square-\text { Square; } p / e=10 \\
& -\square . \text { Rectangular } w / e=0.5 ; p / e=10 \\
& -\square-\text { Rectangular } w / e=2 ; p / e=10 \\
& -\diamond . \text { Trapezoidal iso; } p / e=10 \\
& -\diamond-\text { Trapezoidal rect; } p / e=10 \\
& -\Delta . \text { Triangular } w / e=1 ; p / e=8 \\
& -\Delta-\quad \text { Triangular } w / e=2 ; p / e=8
\end{aligned}
$$

(b)

Figure 10: Profiles as a function of Reynolds numbers in the range 20000-60000 at $e / d=0.05$ for different rib shapes and significant pitches: (a) average Nusselt number and (b) friction factor.

low velocities the friction factor coefficient tends to increase as Reynolds number increases rapidly until $\mathrm{Re}=40000$. From this value of $\mathrm{Re}$, the profile seems to tend to an asymptotic, constant value, termed fully rough condition, which depends on the height of the roughness. The introduction of the ribbed elements in the channel yields to higher friction factor. The highest values are evaluated for the triangular shape with $w / e=1.0$ while the lowest are detected for the rectangular shape with $w / e=2.0$ and for trapezoidal ones. At Reynolds number equal to 60000 the friction factor is 7 times greater than the value referred to the smooth duct at least and 18 times at most.

The required pumping power increases more than linearly as Reynolds number increases as depicted in Figure 11(a); furthermore, it is equal to about 13 times greater than the smooth channel one at most and 8.5 times at least at $\operatorname{Re}=60000$, as shown in Figure 11(b).

Figures 12 and 13 depict the flow pattern in the interrib region at $\operatorname{Re}=20000$ and 60000 for different shapes, such as square, rectangular with $w / e=0.5$, triangular with $w / e=1.0$ and trapezoidal ones, in order to clearly show the eddy formation, adjacent to the rib when the flow is stabilized for small pitches. The stabilization happens after 4-5 ribs, such as when the vortex structures tend to repeat almost similarly from this zone. Figure 12(a) refers to the behavior at lower pitch ratio $(p / e<6)$ for a square-ribbed channel at $\operatorname{Re}=20000$ and 50000. It exhibits a d-type roughness behavior: a single eddy is trapped between adjacent ribs and hinders the heat transfer. As a result, the outer flow is relatively disturbed by the roughness elements. The letter $d$ denotes the significant length scale, linked to the boundary layer thickness, channel hydraulic diameter or channel height. Pressure drops are relatively high and the heat transfer enhancement low. A similar behavior is detected for the other shapes ribs as shown in Figure 13(a) where it is clear that the flow difficultly penetrates into 

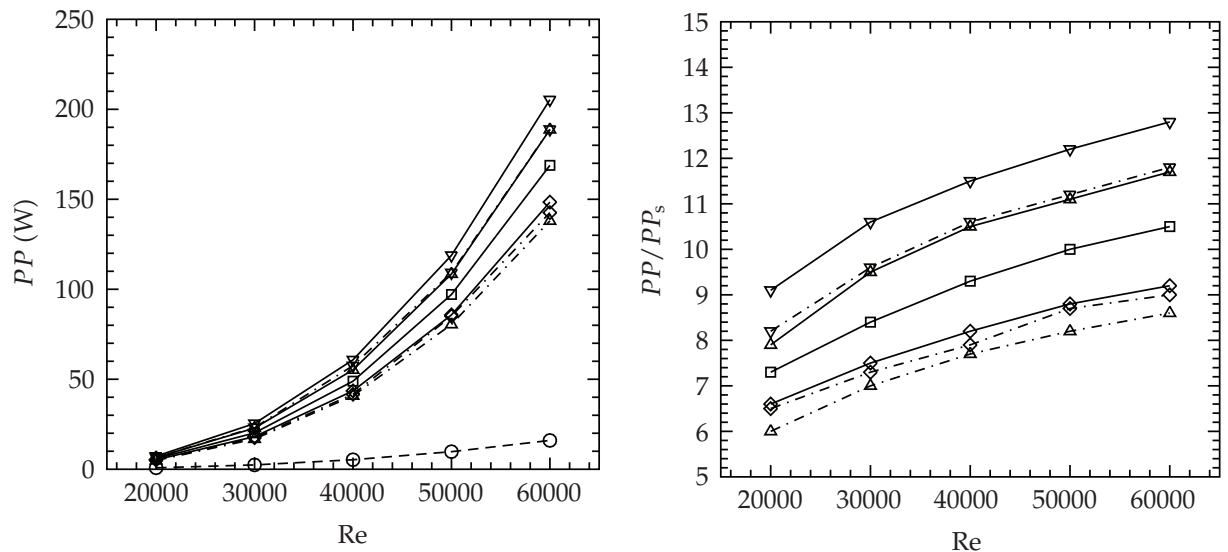

$$
\begin{aligned}
& e / d=0.05 \\
& \square-\text { Square; } p / e=12 \\
& \triangle-\text { Rectangular } w / e=0.5, p / e=10 \\
& -\Delta \cdot \text { Rectangular } w / e=2, p / e=10 \\
& \rightarrow-\text { Triangular } w / e=1, p / e=8 \\
& -\nabla . \text { Triangular } w / e=2, p / e=8 \\
& \diamond-\text { Trapezoidal iso, } p / e=10 \\
& -\diamond . \text { Trapezoidal rect, } p / e=10 \\
& -\diamond . \text { Smooth }
\end{aligned}
$$

(a)

$$
\begin{aligned}
& e / d=0.05 \\
& \square-\text { Square; } p / e=12 \\
& \varangle \quad \text { Rectangular } w / e=0.5, p / e=10 \\
& -\triangleleft . \text { Rectangular } w / e=2, p / e=10 \\
& \rightarrow-\text { Triangular } w / e=1, p / e=8 \\
& -\nabla \cdot \text { Triangular } w / e=2, p / e=8 \\
& \diamond-\text { Trapezoidal iso, } p / e=10 \\
& -\diamond . \text { Trapezoidal rect, } p / e=10
\end{aligned}
$$

(b)

Figure 11: Profiles as a function of Reynolds numbers in the range $20000-60000$ at $e / d=0.05$ for different rib shapes and significant pitches: (a) required pumping power and (b) pumping power referred to the smooth channel results.
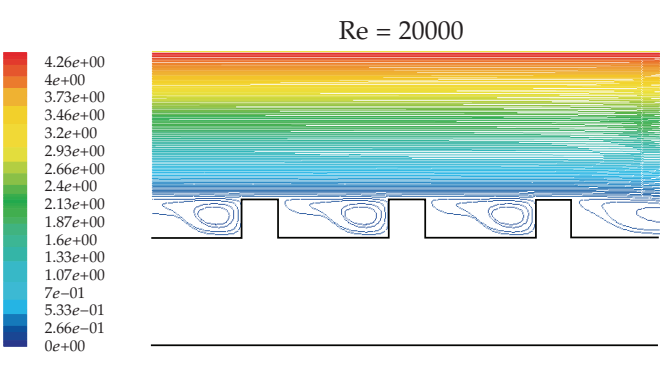

(a)
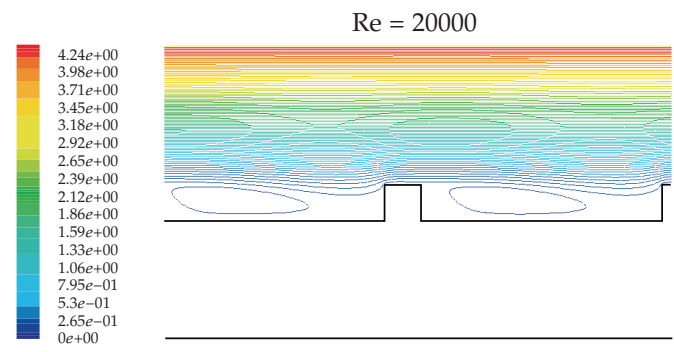
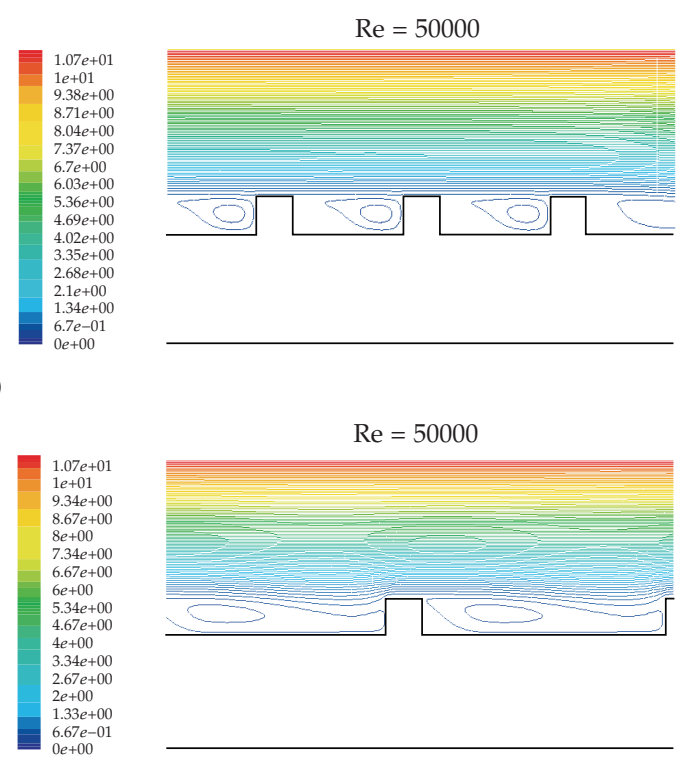

$\operatorname{Re}=50000$

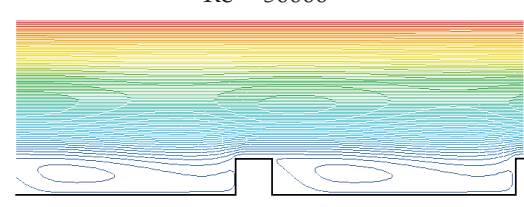

(b)

Figure 12: Stream function contours at $\operatorname{Re}=20000$ and 50000, for square-ribs, $e / d=0.05$ : (a) $p / e=4$ and (b) $p / e=8$. 
Rectangular ribs $(w / e=0.5)$

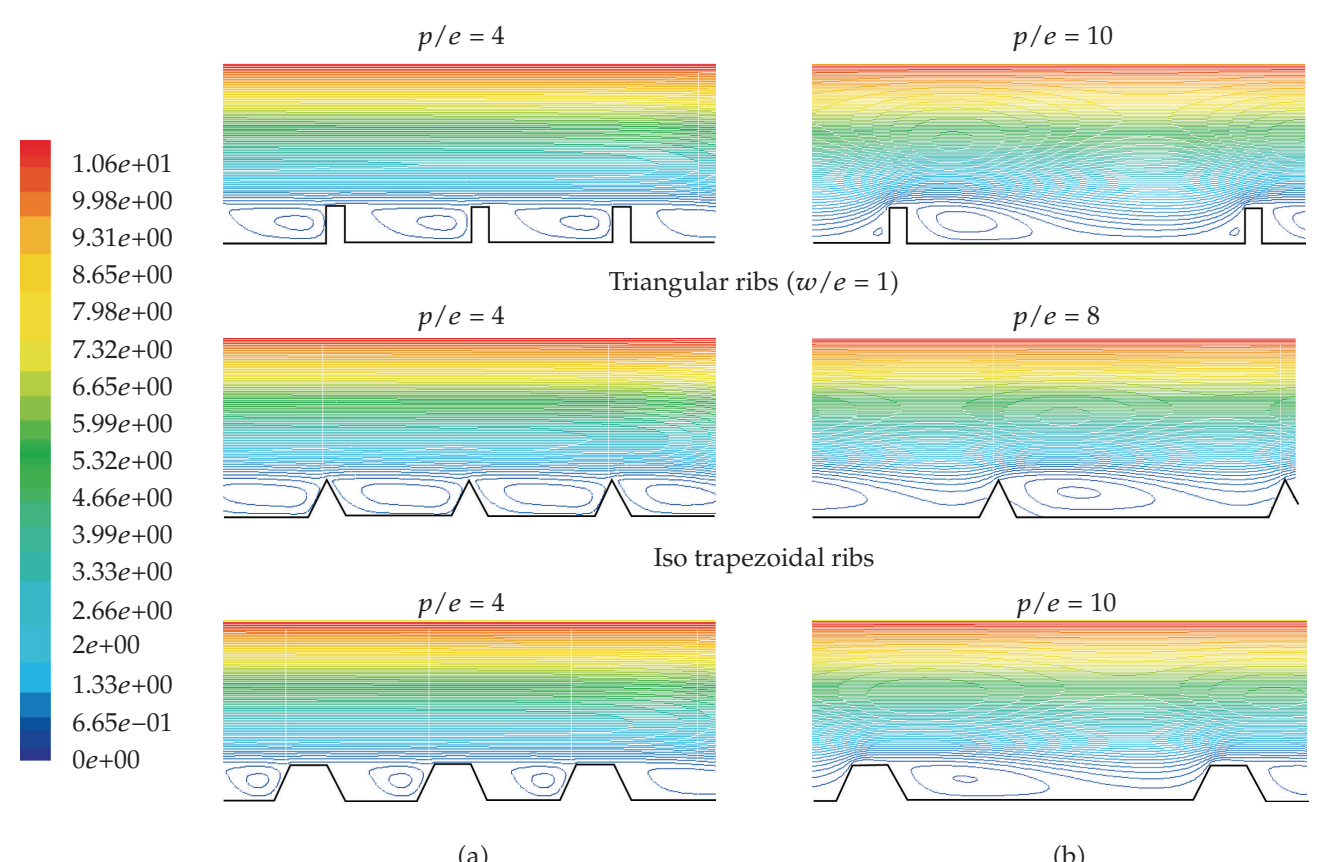

(a)

(b)

Figure 13: Stream function contours at $\operatorname{Re}=50000$ and different significant pitches, for square, rectangular $(w / e=0.5)$, triangular $(w / e=1.0)$ and iso trapezoidal ribs, $e / d=0.05$ : (a) $d$-type behavior and (b) $k$-type behaviour.

the cell between two adjacent ribs also for $\mathrm{Re}=50000$, except for the triangular elements in which the entrapment of fluid, due to the adjacent turbulators, is lower. Moreover, vortex intensity augments as Re and $e / d$ ratio increase as described in Figures 12(a) and 12(b).

Figures 12(b) and 13(b) depict the stream function contours for square-ribs at $\operatorname{Re}=$ 20000 and 50000 and rectangular $(w / e=0.5)$, triangular $(w / e=1.0)$ and iso trapezoidal ones at $\operatorname{Re}=50000$, respectively, for $p / e>6$. They clarifies the $k$-type roughness behavior: the value of $p / e$ increases and the stream functions change; the $y$-velocity gradient reduces along the fluid direction and the flow separates then it reattaches after six-to-eight rib heights downstream from the turbulators. Near this point, the Nusselt number is expected to be maximum as well as the friction factor. The length scale for $k$-type is the roughness height and the eddies penetrate into the bulk flow toward boundary layer, promoting a more intense turbulent mixing.

Figure 14 reports the dimensionless temperature fields for significant pitches at $\operatorname{Re}=$ 50000 for the configuration with square, rectangular $(w / e=0.5)$, triangular $(w / e=2.0)$, iso and rect trapezoidal ribs, characterized by $e / d=0.05$. Dimensionless temperature, $T^{*}$, is defined by the following relation:

$$
T^{*}=\frac{\left(T-T_{m, \text { in }}\right)}{\left(T_{m, \text { out }}-T_{m, \text { in }}\right)} .
$$

Figure 14 depicts the temperature field for square-ribs, typically observed for configurations, characterized by a $d$-type behaviour since the value of $p / e$ is equal to 4 , and $k$-type one for 

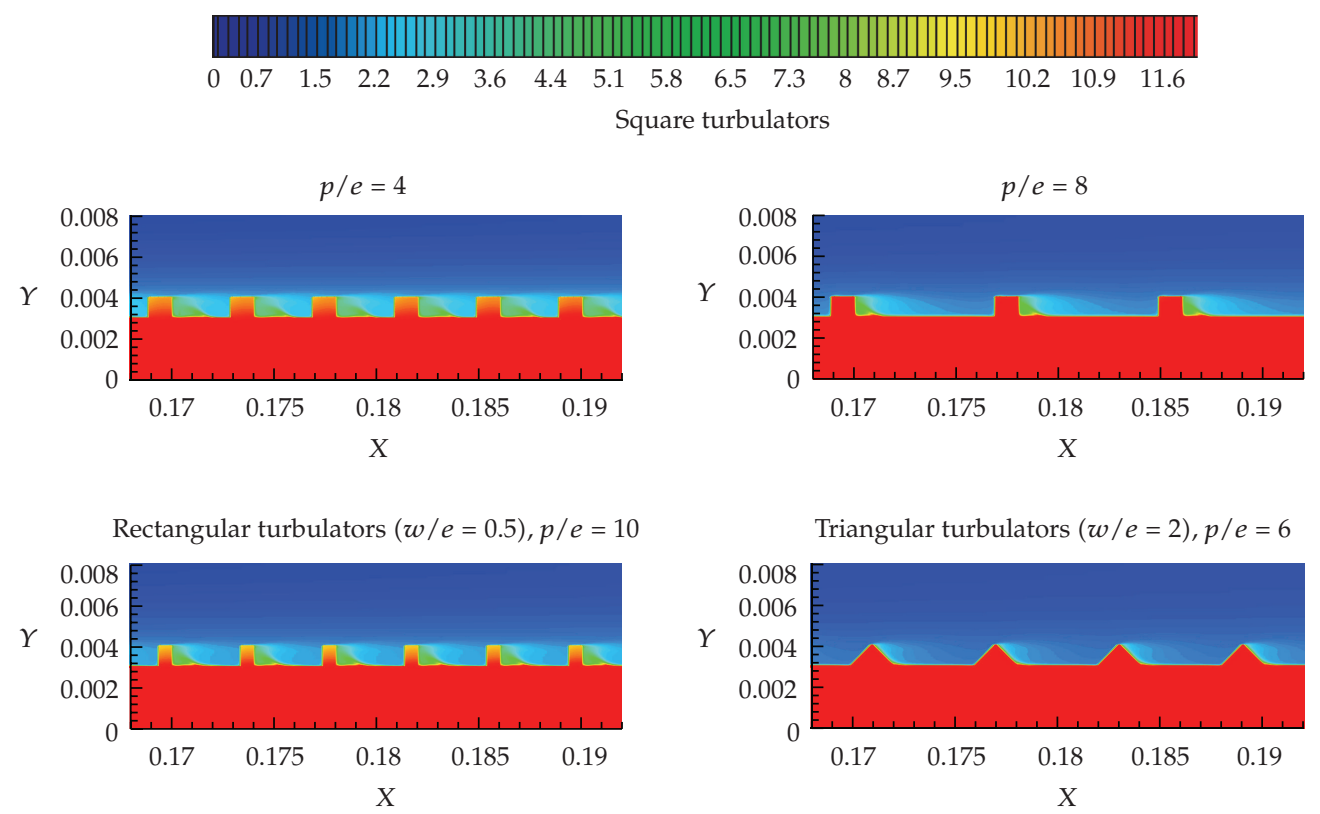

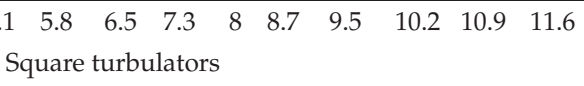
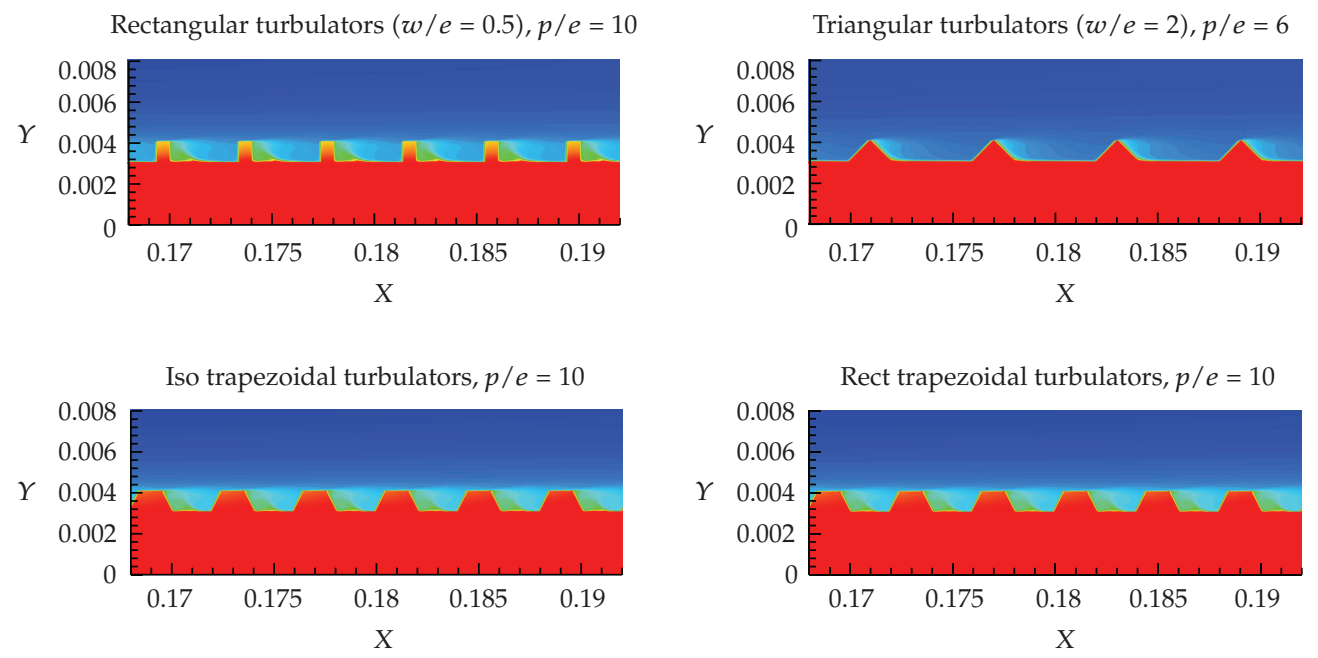

Figure 14: Temperature fields at $\operatorname{Re}=50000$ and different significant pitches, for square, rectangular $(w / e=$ $0.5)$, triangular $(w / e=2.0)$ and trapezoidal ribs, $e / d=0.05$.

$p / e=8$. In the figure on the left, the fluid temperature is very high near the rib-wall juncture behind the turbulator but the fluid in the core region is poorly influenced, because of the recirculation entrapped into the interrib zone. For $p / e=8$, such as for a configuration which exhibits a $k$-type behaviour, the mixing effects are stronger and the average temperature also in the core region is higher; as a result, the difference between the average temperature of fluid and wall decreases and the heat transfer mechanism becomes more efficient, as also described for the rectangular shape $(w / e=0.5)$ at $p / e=10$, iso and rect trapezoidal turbulators at $p / e=10$. The triangular elements show the best thermal performances also for low values of pitches in comparison with the other shapes, such as at $p / e=6$; in fact, low values of $p / e$ does not badly affect the heat transfer mechanism, because of water conductivity and rough element geometry, as noticed for the other shapes of turbulators. Moreover, figures show that the temperature is lowest on the windward face of the rib, and highest on the leeward face, while heat flux is highest on the front face and lowest on the back face.

\section{Conclusions}

In this paper, a ribbed channel with square, rectangular, triangular, and trapezoidal turbulators, characterized by different geometric ratios and heights has been analyzed by means 
of FLUENT code. The external walls are heated by a constant heat flux and the flow regime is turbulent. The aim of the investigation consists into find out the optimal pitch of ribs at different Reynolds number, between 20000 and 60000, in order to ensure the maximum heat transfer rate and contain losses.

Simulations show that maximum average Nusselt numbers are detected in correspondence with $p / e$ ratio equal to 6,8 , and 10, for triangular, square, rectangular and trapezoidal ribs, respectively. The average Nusselt number values increase as Reynolds number and $e / d$ grow and they are at most equal to 2.6 times greater than the smooth channel results. Furthermore, the friction factor is the highest at $p / e=10$ for the rectangular, trapezoidal and square-ribs while the triangular ones show the maximum values at $p / e=8$; it increases as Re and $e / d$ increases as well as the required pumping power. For $\operatorname{Re}>40000$ an asymptotic behavior is detected. The most significant thermal performances are provided by triangular ribs with $w / e=2.0$, while the weakest ones are detected for the rectangular shape with $w / e=2.0$, which present the lowest friction factor values, on the other hand. Finally, temperature fields and stream function contours are given in order to visualize the temperature distribution and flow pattern in presence of $d$-type and $k$-type roughness behavior also for triangular ribs.

\section{Nomenclature}

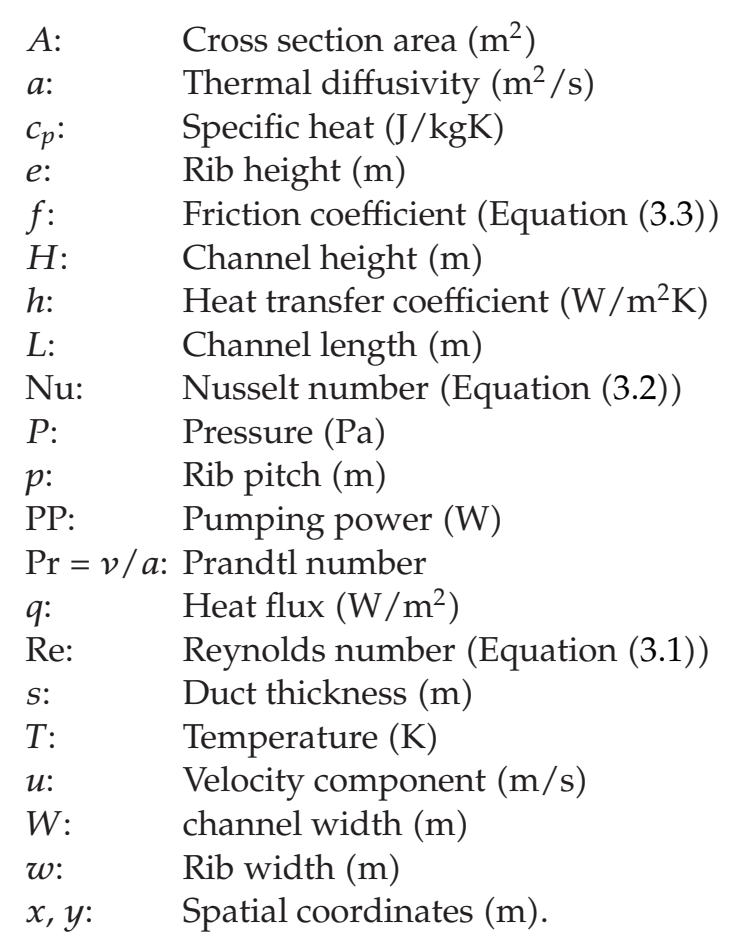

\section{Greek Symbols}

$\lambda$ : Thermal conductivity $(\mathrm{W} / \mathrm{mK})$

$\mu$ : Dynamic viscosity (Pas)

$\rho$ : Density $\left(\mathrm{kg} / \mathrm{m}^{3}\right)$ 
d: Hydraulic diameter (m)

$\sigma$ : Turbulent Prandtl number

$\tau$ : Wall shear stress $(\mathrm{kg} / \mathrm{m})$

$v$ : kinematic viscosity $\left(\mathrm{m}^{2} / \mathrm{s}\right)$.

\section{Subscripts}
a: Ambient
av: Average
$f$ : Fluid
$i, j$ : Components
in: Inlet section
$m$ : Mass
out: Outlet section
s: Smooth
sl: Solid
$t$ : Turbulent
$w$ : Wall.

\section{Acknowledgment}

This work was supported by SUN with a 2008 Grant and by MIUR with Articolo D.M. 593/ 2000 Grandi Laboratori "EliosLab".

\section{References}

[1] A. E. Bergles, W. M. Rohsenow, J. P. Hartnett, and E. Ganie, Techniques to Augment Heat Transfer, Handbook of Heat Transfer Application, McGraw Hill, New York, NY, USA, 1985.

[2] A. E. Bergles, "Some perspective on enhanced heat transfer-second-generation heat transfer technology," Journal of Heat Transfer, vol. 110, no. 4, pp. 1082-1096, 1988.

[3] R. L. Webb and N. H. Kim, Principles of Enhanced Heat Transfer, Taylor \& Francis, New York, NY, USA, 2nd edition, 2005.

[4] R. L. Webb, "Advances in shell side boiling of refrigerants," Proceedings of the Institute of Refrigeration, vol. 87, pp. 75-86, 1990.

[5] R. L. Webb and G. F. Robertson, "Shell-side evaporators and condensers used in the refrigeration industry," in Heat Transfer Equipment Design, R. K. Shah, E. C. Subbarao, and R. A. Mashelkar, Eds., pp. 559-570, Hemisphere Pub. Corp., Washington, DC, USA, 1988.

[6] H. M. Jaber, R. L. Webb, and P. Stryker, “Experimental investigation of enchanced tubes for steam condensers," in National Heat Transfer Conference, pp. 1-8, July 1991.

[7] B. Sunden and G. Xie, "Gas turbine blade tip heat transfer and cooling: a literature survey," Heat Transfer Engineering, vol. 31, no. 7, pp. 527-554, 2010.

[8] K. B. Muluwork, S. C. Solanky, and J. S. Saini, "Study of heat transfer and friction in solar air heaters roughened with staggered discete ribs," in Proceedings of the 4th ISHMT-ASME Heat and Mass Transfer Conference, pp. 391-398, Pune, India, 2000.

[9] R. Karwa, S. C. Solanki, and J. S. Saini, "Thermo-hydraulic performance of solar air heaters having integral chamfered rib roughness on absorber plates," Energy, vol. 26, no. 2, pp. 161-176, 2001.

[10] C. Thianpong, T. Chompookham, S. Skullong, and P. Promvonge, "Thermal characterization of turbulent flow in a channel with isosceles triangular ribs," International Communications in Heat and Mass Transfer, vol. 36, no. 7, pp. 712-717, 2009. 
[11] R. Kamali and A. R. Binesh, "The importance of rib shape effects on the local heat transfer and flow friction characteristics of square ducts with ribbed internal surfaces," International Communications in Heat and Mass Transfer, vol. 35, no. 8, pp. 1032-1040, 2008.

[12] D. Giupta, Investigations on fluid flow and heat transfer in solar air heaters with roughened absorbers, Ph.D. thesis, University of Roorkee, India, 1993.

[13] R. Karwa, S. C. Solanki, and J. S. Saini, "Heat transfer coefficient and friction factor correlations for the transitional flow regime in rib-roughened rectangular ducts," International Journal of Heat and Mass Transfer, vol. 42, no. 9, pp. 1597-1615, 1999.

[14] T. M. Liou and J. J. Hwang, "Turbulent heat transfer augmentation and friction in periodic fully developed channel flows," Journal of Heat Transfer, vol. 114, no. 1, pp. 56-64, 1992.

[15] T.-M. Liou and J.-J. Hwang, "Effect of ridge shapes on turbulent heat transfer and friction in a rectangular channel," International Journal of Heat and Mass Transfer, vol. 36, no. 4, pp. 931-940, 1993.

[16] G. Tanda, "Heat transfer in rectangular channels with transverse and V-shaped broken ribs," International Journal of Heat and Mass Transfer, vol. 47, no. 2, pp. 229-243, 2004.

[17] C. K. Lee and S. A. Abdel-Moneim, "Computational analysis of the heat transfer in turbulent flow past a horizontal surface with two-dimensional ribs," International Communications in Heat and Mass Transfer, vol. 28, no. 2, pp. 161-170, 2001.

[18] J. Nikuradse, "Laws of Flow in Rough Pipes," National Advisory Committee for Aeronautics Technical Memorandum 1292, 1950.

[19] D. F. Dipprey and R. H. Sabersky, "Heat and momentum transfer in smooth and rough tubes at various prandtl numbers," International Journal of Heat and Mass Transfer, vol. 6, no. 5, pp. 329-353, 1963.

[20] R. L. Webb, E. R. G. Eckert, and R. J. Goldstein, “Heat transfer and friction in tubes with repeated-rib roughness," International Journal of Heat and Mass Transfer, vol. 14, no. 4, pp. 601-617, 1971.

[21] B. K. Lee, N. H. Cho, and Y. D. Choi, "Analysis of periodically fully developed turbulent flow and heat transfer by $\mathrm{k}-\varepsilon$ equation model in artificially roughened annulus," International Journal of Heat and Mass Transfer, vol. 31, no. 9, pp. 1797-1806, 1988.

[22] B. Arman and T. J. Rabas, "Disruption share effects on the performance of enhanced tubes with the separation and reattachment mechanism," in Proceedings of the 28th National Heat Transfer Conference and Exhibition, pp. 67-75, August 1992.

[23] S. Acharya, S. Dutta, T. A. Myrum, and R. S. Baker, "Periodically developed flow and heat transfer in a ribbed duct," International Journal of Heat and Mass Transfer, vol. 36, no. 8, pp. 2069-2082, 1993.

[24] R. Manceau, S. Parneix, and D. Laurence, "Turbulent heat transfer predictions using the $\overline{v^{2}}-f$ model on unstructured meshes," International Journal of Heat and Fluid Flow, vol. 21, no. 3, pp. 320-328, 2000.

[25] G. Iaccarino, A. Ooi, P. A. Durbin, and M. Behnia, "Conjugate heat transfer predictions in twodimensional ribbed passages," International Journal of Heat and Fluid Flow, vol. 23, no. 3, pp. 340-345, 2002.

[26] D. K. Tafti, "Evaluating the role of subgrid stress modeling in a ribbed duct for the internal cooling of turbine blades," International Journal of Heat and Fluid Flow, vol. 26, no. 1, pp. 92-104, 2005.

[27] A. Slanciauskas, "Two friendly rules for the turbulent heat transfer enhancement," International Journal of Heat and Mass Transfer, vol. 44, no. 11, pp. 2155-2161, 2001.

[28] T. M. Liou, J. J. Hwang, and S. H. Chen, "Simulation and measurement of enhanced turbulent heat transfer in a channel with periodic ribs on one principal wall," International Journal of Heat and Mass Transfer, vol. 36, no. 2, pp. 507-517, 1993.

[29] G. Rau, M. Çakan, D. Moeller, and T. Arts, "The effect of periodic ribs on the local aerodynamic and heat transfer performance of a straight cooling channel," Journal of Turbomachinery, vol. 120, no. 2, pp. 368-375, 1998.

[30] L. Wang and B. Sundén, "Experimental investigation of local heat transfer in a square duct with various-shaped ribs," Heat and Mass Transfer/Waerme- und Stoffuebertragung, vol. 43, no. 8, pp. 759766, 2007.

[31] S. W. Ahn, "The effects of roughness types on friction factors and heat transfer in roughened rectangular duct," International Communications in Heat and Mass Transfer, vol. 28, no. 7, pp. 933-942, 2001.

[32] D. N. Ryu, D. H. Choi, and V. C. Patel, "Analysis of turbulent flow in channels roughened by twodimensional ribs and three-dimensional blocks. Part I: resistance," International Journal of Heat and Fluid Flow, vol. 28, no. 5, pp. 1098-1111, 2007. 
[33] D. N. Ryu, D. H. Choi, and V. C. Patel, "Analysis of turbulent flow in channels roughened by twodimensional ribs and three-dimensional blocks. Part II: heat transfer," International Journal of Heat and Fluid Flow, vol. 28, no. 5, pp. 1112-1124, 2007.

[34] A. Chaube, P. K. Sahoo, and S. C. Solanki, "Analysis of heat transfer augmentation and flow characteristics due to rib roughness over absorber plate of a solar air heater," Renewable Energy, vol. 31, no. 3, pp. 317-331, 2006.

[35] O. Manca, S. Nardini, and D. Ricci, "Numerical investigation of air forced convection in channels with differently shaped transverse ribs," International Journal of Numerical Methods for Heat and Fluid Flow, vol. 21, no. 5, 2010.

[36] Fluent corporation, "Fluent v6.3 user guide," 2006.

[37] F. R. Menter, "Two-equation eddy-viscosity turbulence models for engineering applications," AIAA journal, vol. 32, no. 8, pp. 1598-1605, 1994.

[38] W. M. Rohsenow, J. P. Hartnett, and Y. I. Cho, Handbook of Heat Transfer, McGraw-Hill, New York, NY, USA, 3rd edition, 1998.

[39] F. P. Incropera, P. D. Witt, T. L. Bergman, and A. S. Lavine, Fundamentals of Heat and Mass Transfer, John Wiley \& Sons, Hoboken, NJ, USA, 5th edition, 2007. 


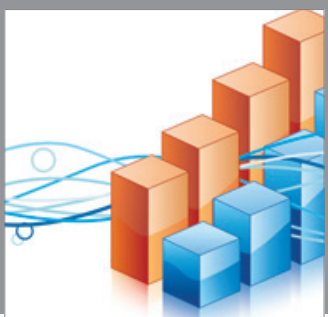

Advances in

Operations Research

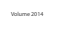

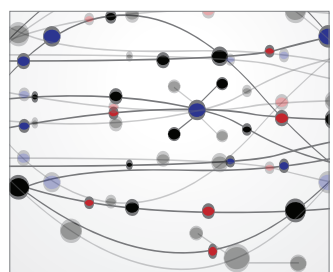

\section{The Scientific} World Journal
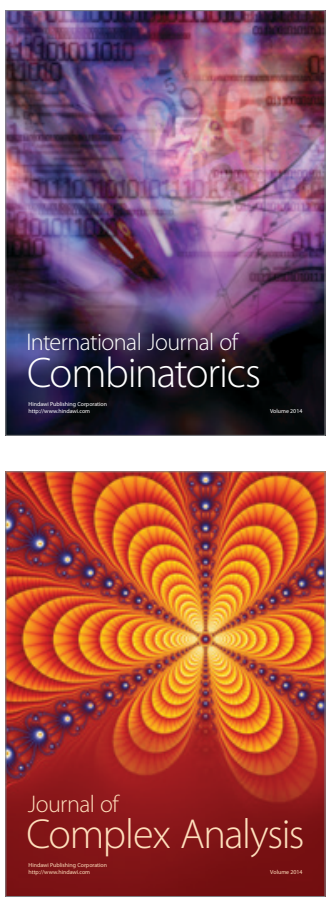

International Journal of

Mathematics and

Mathematical

Sciences
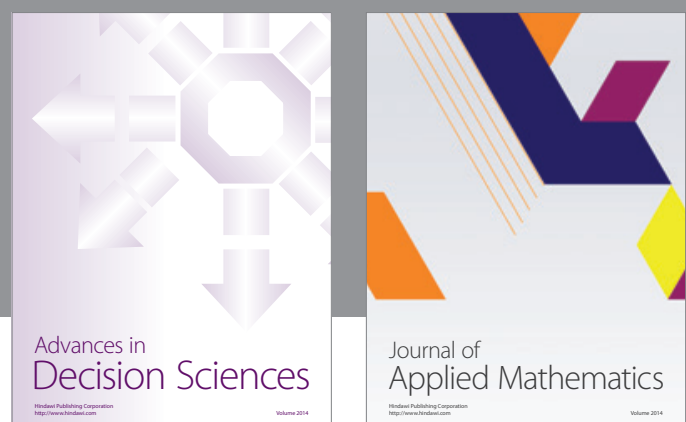

Journal of

Applied Mathematics
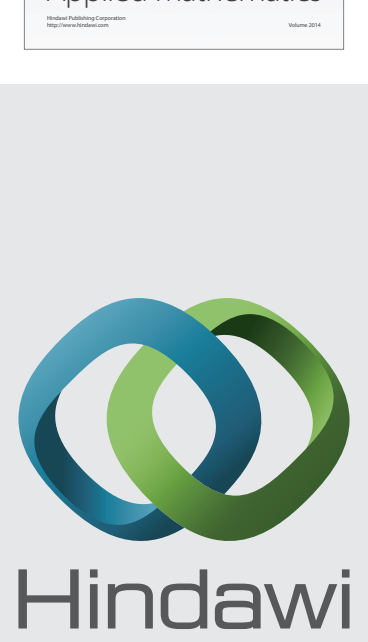

Submit your manuscripts at http://www.hindawi.com
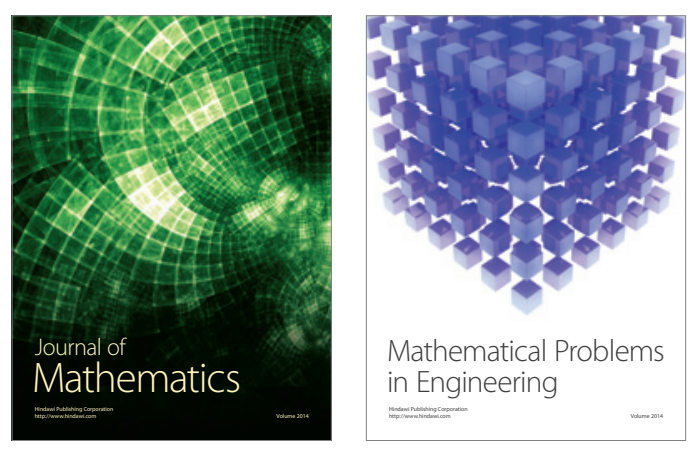

Mathematical Problems in Engineering
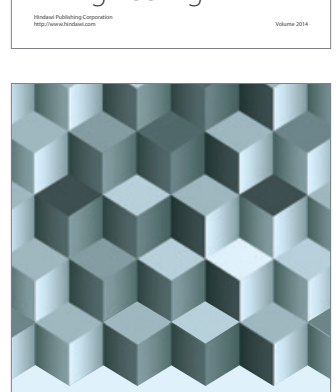

Journal of

Function Spaces
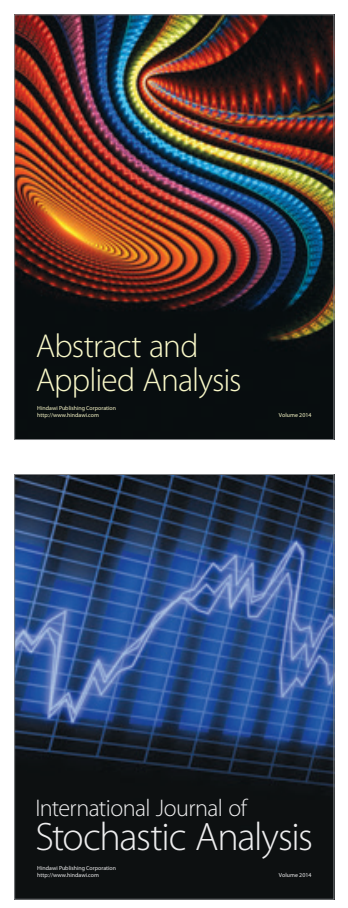

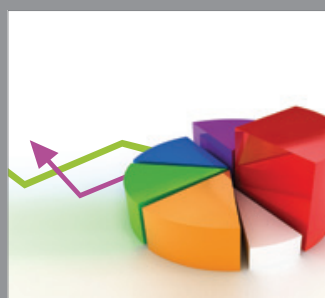

ournal of

Probability and Statistics

Promensencen
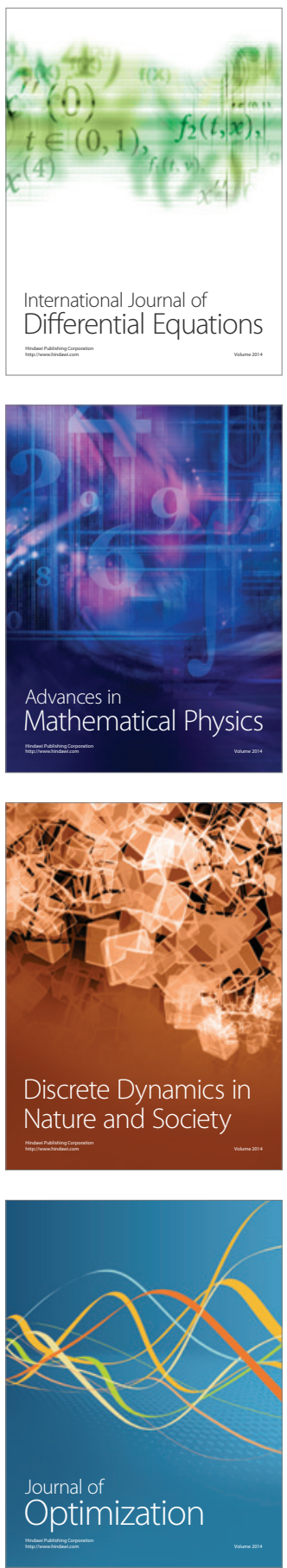